\title{
تأثير أسلوب فنية التعاهل هم الحياة في خفض قلق البطالة لدى الشباب في هحافظة بغداد
}

\author{
أ.م.د. هدية جاسم حسنز ظاهر \\ الكلية التزبوبة المفتوهة / بـغداد \\ مطفص البمث : \\ يهاف البحث الحالي التعرف على:( تأثير فنية التعامل مع الحياة في خفض قلق البطالة لدى الشباب) من خلال اختبار فرضيات البحث \\ أ-لا توجد فروق ذات دلالة إحصائية في درجات قلق البطالة (للمجموعة الضابطة ) في الاختبارين القبلي والبعدي . \\ ب-لا توجد فروق ذات دلالة إحصائية في درجات قلق البطالة (للمجموعة التجريبية ) في الاختبارين القبلي والبعدي. \\ ج- لا توجد فروق ذات دلالة إحصائية في درجات قلق البطالة للمجموعتين (التجريبية والضابطة ) بعد تطبيق البرنامج في الاختبار البعدي .

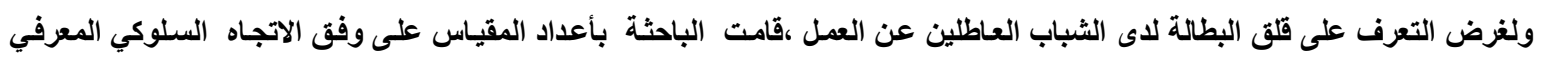

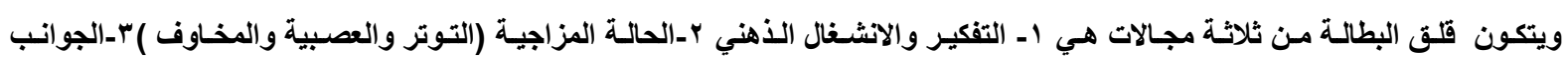

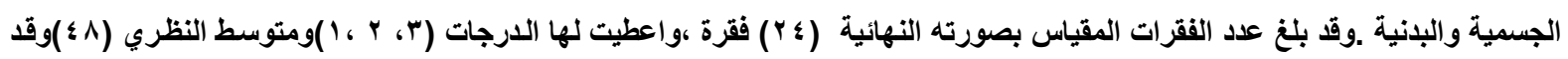 \\ بلغت اعلى درجة في المقياس (Y V)وادنى درجة هي (ع Y) ،فقامت الباحثة بعرضه على مجموعة من الخبراء في العلوم التربوية والنفسية.

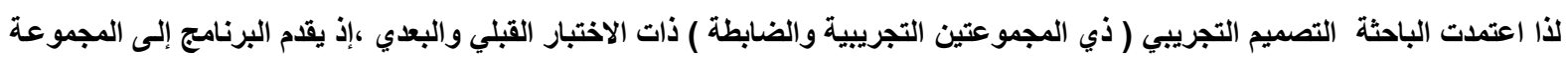

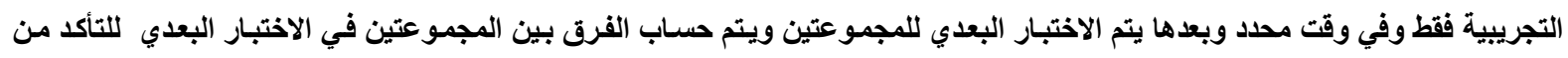

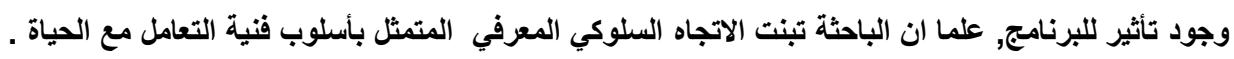

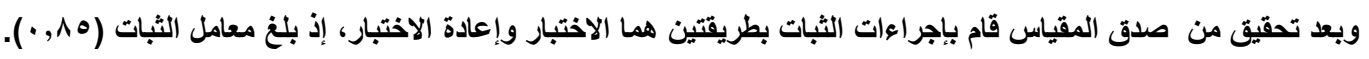

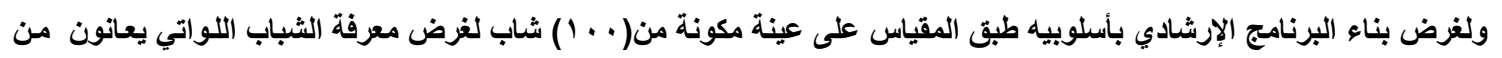

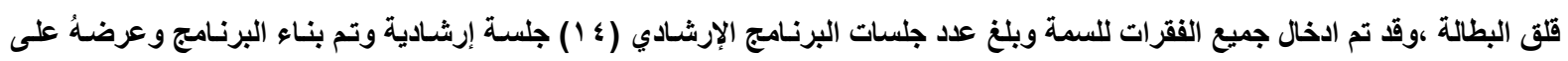

$$
\text { الاساتذة المتخصصين .وقد استعملت الباحثة الحقية الإحصائية . }
$$

The Effect of the (Technique of Coping with Life) Style in Reducing Unemployment Anxiety of Youth in Baghdad

A Research by:

Assist. Prof. Dr.

Hadia Jasim Hassan Tahir

Educational Open College/ Baghdad

Abstract

The current research aims at knowing the impact of the (the technique of coping with life in reducing unemployment anxiety of youth) through testing the following research hypotheses:

1- There no statistically significant differences in the scores of unemployment anxiety (the controlled group) in the pre and post-tests.

$r$ - There no statistically significant differences in the scores of unemployment anxiety (the experimental group) in the pre and post-tests.

r- There no statistically significant differences in the scores of unemployment anxiety (the controlled and experimental groups) after administering the program in the post -test.

In order to know the unemployment anxiety in youth, the researcher has prepared a scale according to the behavioral cognitive trend. The final form of the scale consists of $(r \leqslant)$ items distributed on three components: '-thinking and mental engagement, $r$ - the mood state (tension, nervousness and fears) and $r$-the bodily aspects. In correction, the items are given $(1, r, r)$ where the theoretical means is $(\xi \Lambda)$ and the higher score is $(V r)$ and the lowest is $(r \xi)$. The scale is exposed to a number of experts specialized in educational and psychological sciences.

Accordingly, the researcher the experimental design of (two groups, one experimental and the other is the controlled group) with a pre and post -tests. The program is presented for the experimental

$$
\text { - Y . }
$$


group in a specific time and then the post-test is given for the two groups, after that, the difference between the two is calculated in the post-test in order to ascertain the effect of the program where the researcher has adopted the behavioral cognitive trend represented by (the technique of coping with life).

After ascertaining the validity of the scale, the researcher has conducted the procedure of ascertaining the reliability coefficient of the scale by using two ways, namely, test and re-test, where it is $(\cdot, \wedge \bullet)$.

In order to construct the counseling program with its two styles, it is administered on a sample consists of $(1 \cdots)$ young men in order to know those who suffer from unemployment anxiety, the counseling sessions are $(1 \leqslant)$, exposed on a number of experts. The researcher has used the statistical package (SPSS).

In the light of results, the researcher has put forward a number of recommendations and suggestions.

الفصل الأول: التعريف بالبمث مشـكلة البحث: Research Problem تعد مشكلة قلق البطالـة واحدة مـن أخطر أنـواع المشكلات

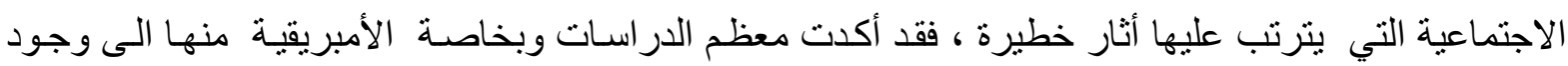
علاقة طردية بين البطالة والأزمات و المشكلات الاجتماعية الاخرى التي تعيشها المجتمعات والتي تقف ور اءهـا أسباب عديدة . وكانت البطالة وماز الت تشكل مصدر قلق اجتماعي حقيقي في الواقع العر اقي ,وهي تمثل انتهاكاً

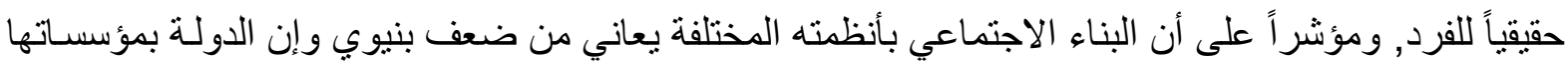
المعنية غير جادة بوضع آلية للتعامل مع نتائج هذه المشكلة خاصة إذا كانت هناك اعتر افات ورؤى متعددة تؤيد بأن البطالة هي حاضنة الإر هاب و التطرف. إن الحد من هذه المشكلة و إيجاد الحلول و المعالجات يتطلب أو لاً

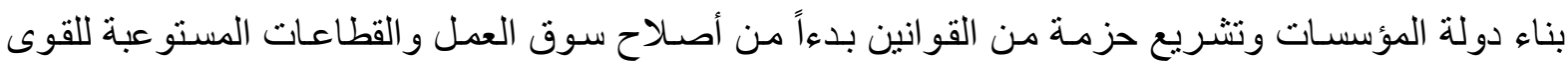
العاملة على مستوى القطاع الصناعي و الزر اعي والقطاع ـ و هذا مـا دفع الباحثة للتصدي إلى هذه المشكلة بالدر اسة والبحث سعيا لإيجاد بر امج إرشادية تهدف إلى خفض قلى البطالة لدى هذه الفئة من الثباب . محددا مشكلة بحثه بالتحقق من تأثثير برنامج إرشادي بفنية التعامل مع الحياة في خفض قلث البطالة لدى الثباب أهمية البحث : Research Important وتركز فنية التعامل مع الحياة على مسـاعدة الفرد على اكتسـاب مهار ات التعايش مع الظروف الحياة اليومية وتطوير المهارات التي من شأنها تسهيل عملية التوافق مع المو اقف

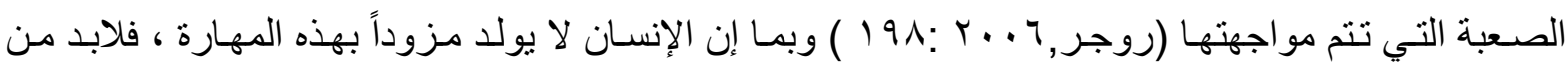

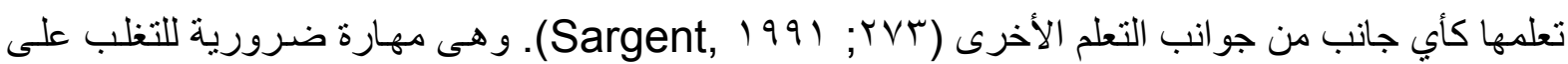
المشكلات السلوكية التي يعانون منها الثباب. أن أهمية تطبيق مختلف الطرق و الأسـاليب الإرشـادية نابعة من اعتقاد نظري وهو أن جانبا ذاتيا من المشكلات التي يعانيها الفرد (النفسية و السلوكية ) ينبع جانبا كبير ا منها من داخل الفرد ولذا فان الطريقة المناسبة لتعديل السلوك وحل المشكلات هو جعل الذات تمر بخبرة تعليميـة، أو

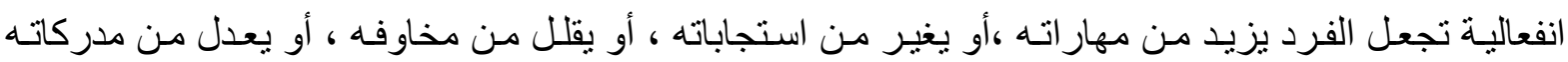

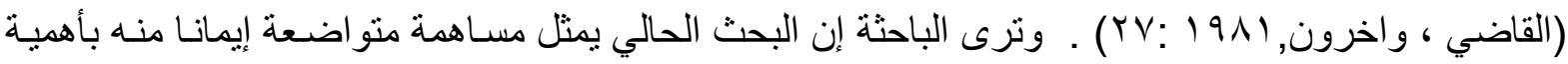

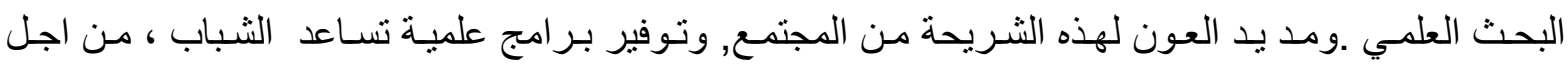
النهوض بهم و الوصول بطاقاتهم وإمكانياتهم إلى أقصى حد مدكن ونأسيساً على ما تقدم فأن أهمية البحث الحالي تكمن في الأمور الآتية : 
1. إن نتائج البحث ستسهر في ألقاء الضوء على مشكله قلق البطالـة ويمكن أن نسهم البرنـامج الإرشـادي في تخفيف من حدته.

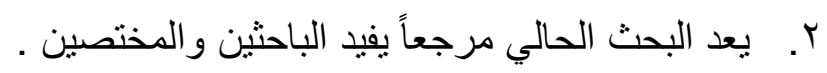
ب.إلقاء الضوء على فنية التعامل مع الحياة وكيفية الاستفادة منها في حل المشكلات السلوكية التي يتعرض لـه الثباب. ثالثاً : أهداف البحث Research Objective: تأثثر فنية التعامل مـع الحياة في خفض قلق البطالة لدى الثباب من خلال اختبار فرضيات البحث الاتية. أـلا توجد فروق ذات دلالـة إحصـائية في درجـات قلق البطالـة (للمجموعـة الضـابطة ) في الاختبـارين القبلي والبعدي .

ب-لا توجد فروق ذات دلالنة إحصـائية في درجـات قلق البطالـة (للمجموعـة التجريبية) في الاختبارين القبلي والبعدي. ج- لا توجد فروق ذات دلالة إحصائية في درجات قلق البطالة للمجمو عتين (التجريبية و الضـابطة ) بعد تطبيق البرنامج في الاختبار البعدي . حدود البحث: يتحدد البحث الحسالي الثباب الخريجين الذين لم يتعينون على دوائر الدولة او القطاع الخاص

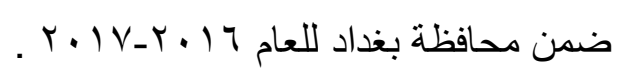
تحديد المصطلحات: أولا- فية التعامل مع الحياة: 1911

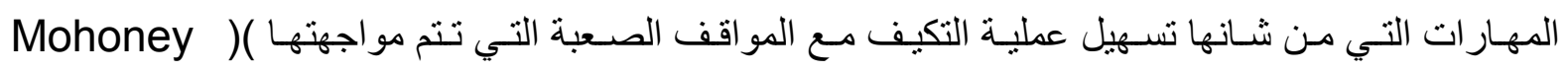
( $10 \mathrm{~V}: 1911$ القريوتي، والسرطاوي 990 (: (مسـاعدة الفرد على التعايش مـع قدراتـه المحدودة المتعلقة بإعاقته وكذللك في

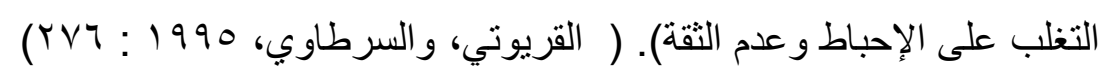
ـ الخطيب ب . . ץ: (تحديد مهار ات التعايش الموجودة لدى الثخص والمهار ات التي يفتقر إليها ,وبعد ذلك تحديد الأسباب التي تكمن وراء العجز الذي يعاني منه الثخص ووضع خطة علاجية مناسبة للتغلب على ذلك )

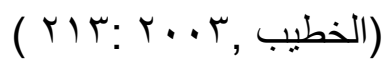
وقد تبنت الباحثة تعريف ماهوني كتعريف نظري . التعريف الإجر ائي : مجموعـة لمو اقف حياتيـة تقدم على شكل أنشطة وتدريبات عمليـة لمفردات البرنـامج الإرشادي التي تتضمن (ع ا ) وحدة زمنية بحيث تستغرق كل وحدة ( مب) دقيقة تقدم لمجموعة من الثباب لغرض خفض قلق البطالة لديهم . 


\section{ثُانيا-قلق البطالة : Anxiety}

ـ ويعرفه مور اي1919 استجابة سلوكية معرفية مرتبطة بصورة مباشـرة بالأفكار و التصسور ات غير المنطقيـة و السلبية و المتمنلة في شكل معتقدات فكرية مثيرة للقلق تظهر على شكل حوار و ألفاظ داخلية يقولها الفرد لنفسـهـ

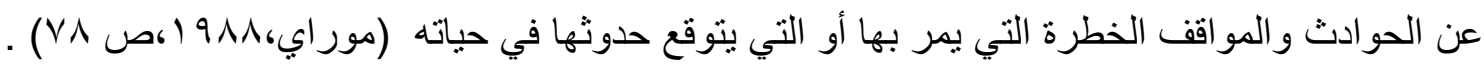
ـالجمال ونجيب^ . . ץ: هو استجابة انفعالية مؤقتة غير سارة وشعور حزين يهد الفرد نتيجة لتوقعاته شبه الأكيدة لثبع البطالة ،و مـا يصـاحبها من توترات ومخـاوف وعدم الاستقر ار الحالـة المزاجية وانشـال الفكر

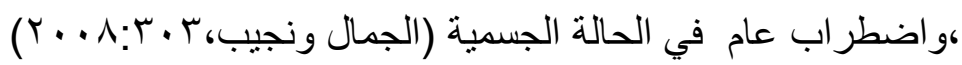
علما ان الباحثة اعتمدت الاتجاه السلوكي المعرفي في بناء المقياس المعد لهذا الغرض.

\section{الفصل الثاني : الإرشاد السلوكي المعرفي : -}

تمثل الأطر النظرية لهذا الاتجاه في الإرشاد النفسي في تلك الأساليب التي قدمها كل من (البرت الس Ellis وأرون بيك Beck وفيكتور رايمي Raimy ومايكل مـاهوني Mahoney) وهم يؤكدون أن الإنسـان كائن فعـال وباحث عن المعلومـات والدليل على كونـه كائنـاً إيجابياً وفعالاً لأنـه على الدوام يبحث عن المعلومـات وينسقها ثم يعالجها، وبعد ذلك يصدر الاستجابة المطلوبـة إز اهها، إن معالجـة المعلومـات عن طريق العمليات العقلية (الإدر الك والتذكر والاستدلال وحل المشكلات والانتباه) و هذه العمليات تسـاعد الإنسـان عند تعرضـه إلى

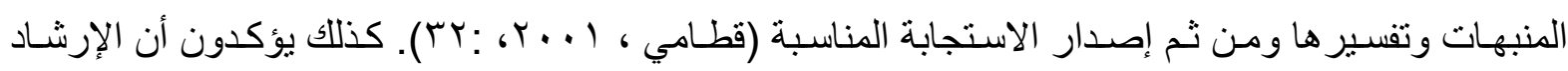

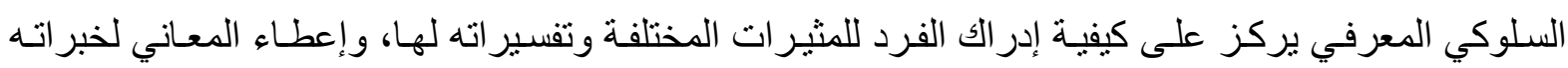
المتعددة، ويرون أن تفكير الفرد خـلال فتر ات الاضطر اب النفسي يصبح أكثر جموداً و أكثر نثويهاً، وتصبح أحكامه مطلقة ويسيطر عليها التعميم الز ائد، كما تصبح المعتقدات الأساسية للفرد حول نفسـه والعـالم من حوله

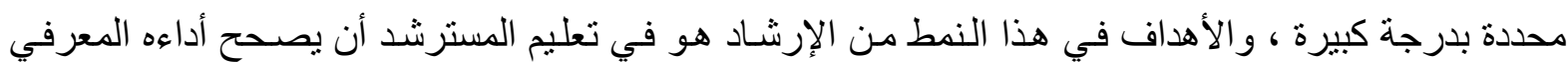

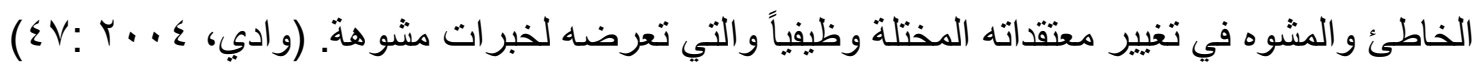
و الإرشاد السلوكي المعرفي منهج إرشادي يستخدم فنيات تعديل السلوك ويدمجها مع مناهج تغيير الاعتقادات غير المتكيفة ، و المرشد هنا يحاول مساعدة المسترشدين على ضبط ردود أفعالهم الانفعالية المزعجة عن طريق

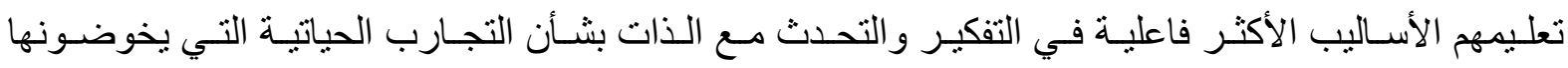
ويرى مـاهوني (Athinson et al, 1997, 077) كثير اً مـا يستخدم الأسلوب السـلوكي المعرفي في الإرشـاد لحل المشكلات وخاصـة تلك التي تتعلق بتعديل السلوك غير المر غوب اجتماعياً وفي اختيار البدائل وللمرشد دور كبير في مساعدة الأفر اد الذين يعانون من التأرجح بين البدائل وهو في هذه الحالة

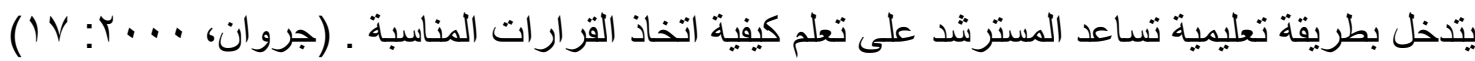
ويذكر عبد الله ( . . rم) أن الإرشاد المعرفي السلوكي يعتبر اتجاهـا إرشـاديا حديثا نسبيا، يعمل على

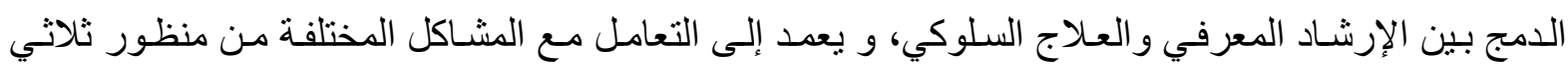

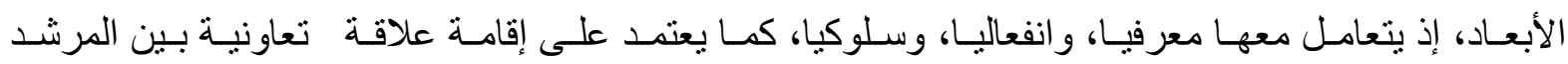


و المسترشد تتحدد في ضو ئها المسئولية الثخصية للمسترشد عن كل ما يعتقده من أفكار مشو هه، واعتقادات لا عقلانية مختلة وظيفيا، تعد هي المسئولة في المقام الأول عن تلك المشـاكل التي يعانيها الفرد، وبنفس المنطق

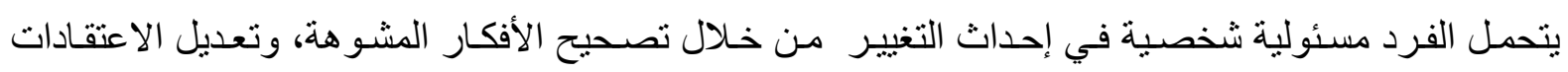

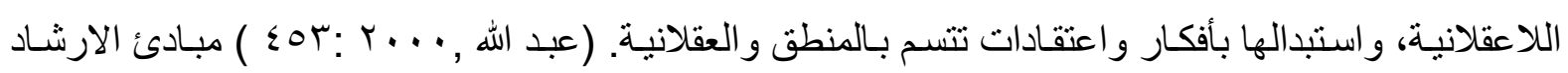
السلوكي المعرفي //إن المرشد و المسترشد يعملان معاً في تقييم المشكلات والتوصل إلى الحلول .

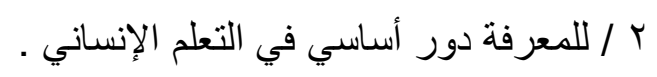

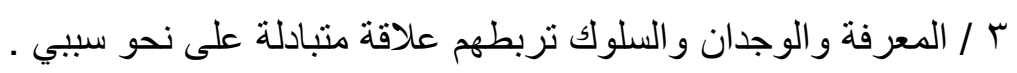

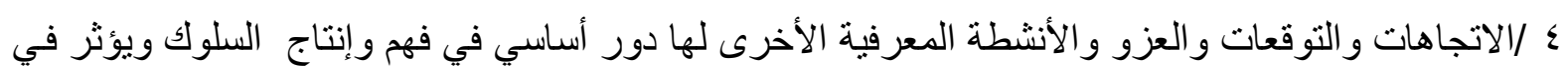
الإرشاد

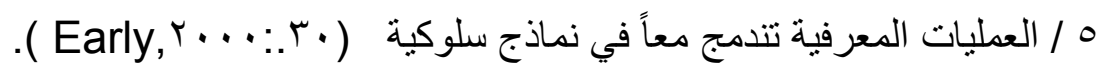

$$
\text { مميزات الإرشاد السلوكي المعرفي }
$$

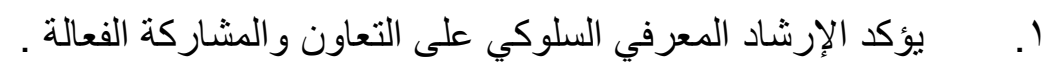

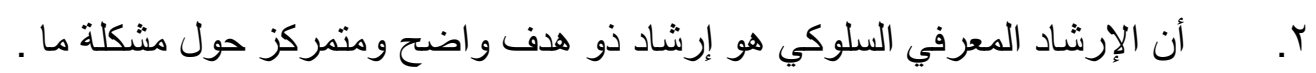
r. بركز الإرشاد المعرفي السلوكي على الحاضر.

ع. الإرشاد السلوكي المعرفي هو تعليمي في الأساس ويهدف إلى تعليم المسترشد كيف يكون مرشدا لنفسه ويركز على تجنب الانتكاسات ( تعلم كيف تتعلم ) .

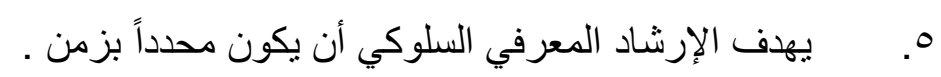

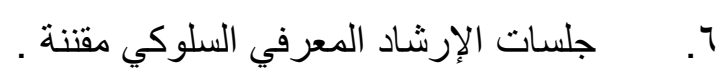

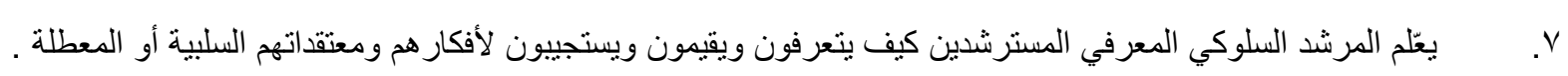

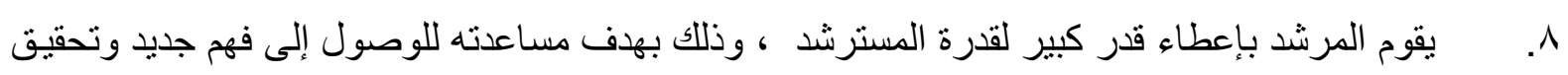

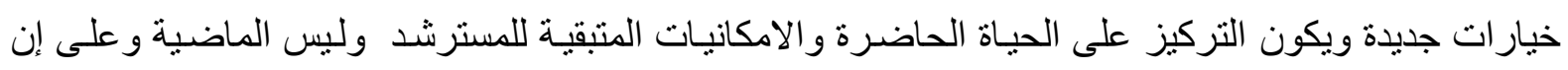
الماضي لا يمكن إصلاحه وخلال الممارسة والتدريب سيظهر المرشد حرية عمل واسعة من خلال الطرق التي

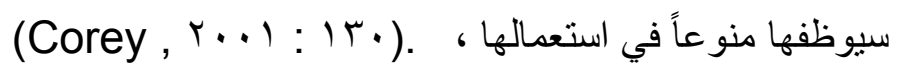
أساليب واستراتيجيات وفنيات الإرشاد السلوكي المعرفي: يشير الخطيب (1991 ) إلى استر اتيجيات وفنيات الإرشاد السلوكي المعرفي :

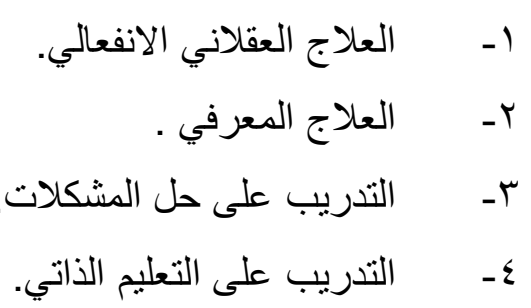




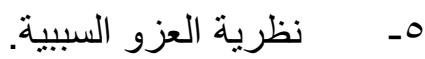

$$
\begin{aligned}
& \text { 7- التعامل مع الحياة (مهار ات التعايش). }
\end{aligned}
$$

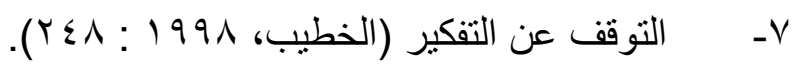

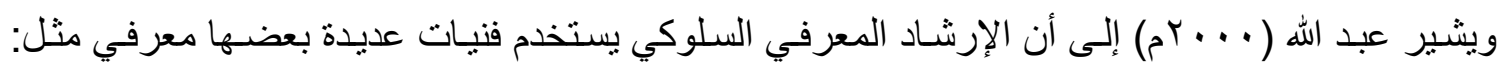

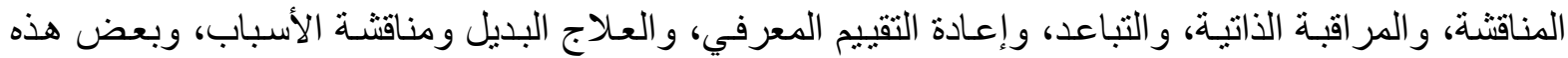
الفنيات تجريبي: كالاستكثـاف الموجه، و التعريض، وبعضـها الآخر سلوكي: كالو اجبات المنزلية، و النمذجـة،

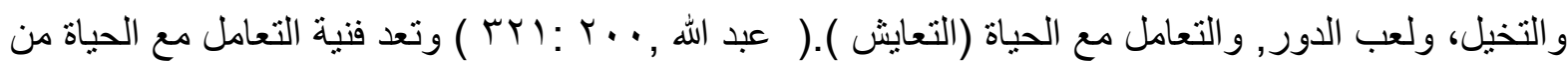
فنيات العلاج السلوكي المعرفي، وتبدأ هذه الفنية بتحديد مهار ات التعايش التي يمتلكها الثنضص و المهارات التي يفتقر إليها ـ ومن فنيات هذا الاسلوب هي كلعب الأدوار و النمذجة وملاحظة الذات و الإيحاء الذاتي .. الخ ـ ولا تركز هذه الفنية على تطوير مهار ات محددة ليؤديها المسترشد في مو اقف معينـة ، بل يركز على تطوير

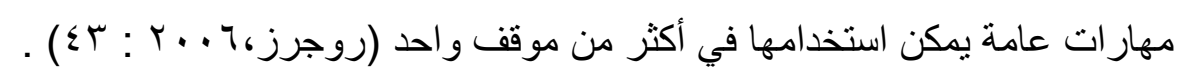

: أهمية فنية التعامل مع الحياة :***

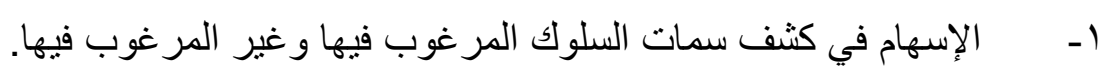

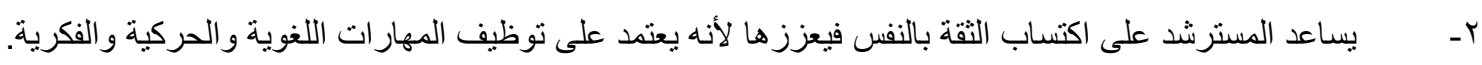

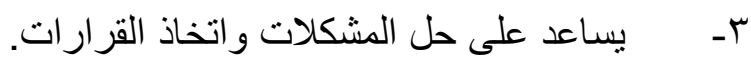

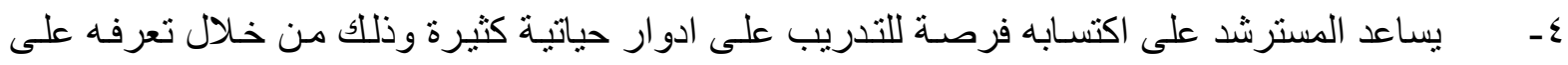

سلوكيات إنسانية ذات أنماط متعددة.

0ـ مساعدة المرشد على اكتشاف ميول المسترشدين ورغباتهم ومن ثم تعديلها.

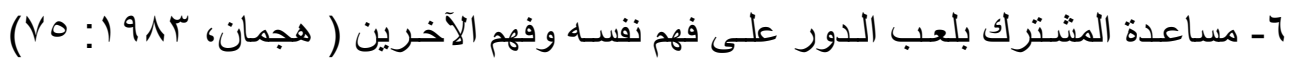

Vـ الممارسة الفعلية في مو اقف حية لتعلم الخبرة الجديدة(إبر اهيم و آخرون، سو 99 (: 17 (1) )

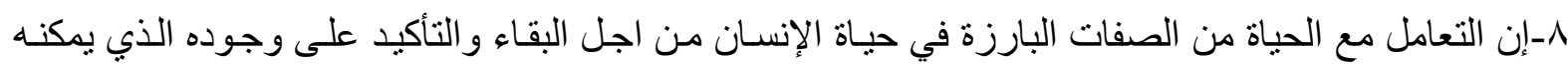

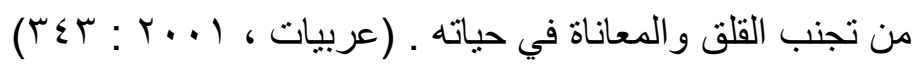

\section{المبادئ العامة لإرشاد الأفراد على مهارات التعامل مع الحياة : - ا - أن يتعرف المتدربون على المهار ات التي سوف يتدربون عليها.

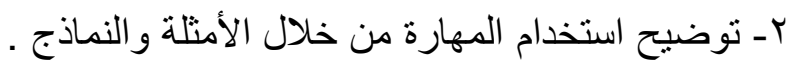
r- قيام المتدربون بأداء الأدو ار مع منحهم فرص التعزيز الاجتماعي، حتى يتمكنو ا من أداء الأدوار بشكل كامل . بل ع- يؤدي المتدربون عدداً من الأدوار بطريقة تمكن المتدربين من أدائها.

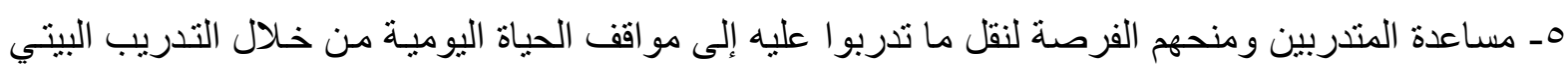
(Goldstein, 19vч: rr) T- مشاركة الآخرين ممن حوله في البيئة لمساعدته على إحراز التقدم . 
V- إعداد جلسات لمتابعة التقدم لدى المتدرب وتزويده بكل ما يحتاجه من تدريبات إضافية.

\section{الفصل الثالث: إجراءات البمث:-}

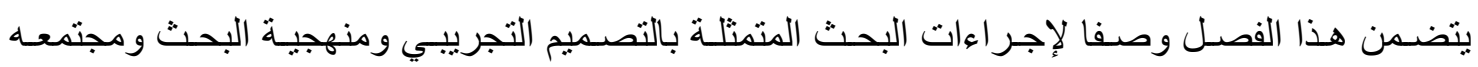
وعينته وأداة البحث و الوسائل الإحصائية المستخدمة في تحليل النتائج . أولا : التصميم التجريبي Experimental design :تعد عملية اختيار التصميم التجريبي الملائم لأهداف

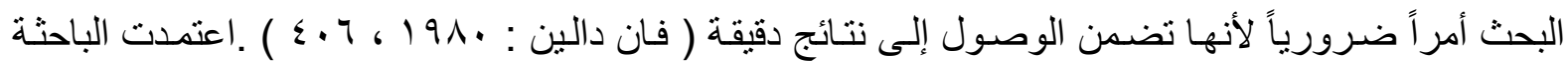
التصميم التجريبي ( ذي المجموعتين التجرييية و الضابطة ) ذات الاختبار القبلي والبعدي ،إذ يقدم البرنـامج إلى . المجموعـة التجريبيـة فقطوفي وقت محدد وبعدها ينت الاختبار البعدي للمجمو عتين ويتم حسـاب الفرق بين المجموعتين في الاختبار البعدي للتأكد من وجود تأثثر للبرنـامج. ولاستخدام هذا التصميم التجريبي تم القيام

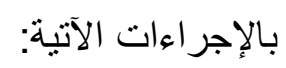

1 - اختيار ( • ) شاب من الذين حصلو ا على أعلى درجات في قلق البطالة r-توزيع أفر اد العينة عشوائيا إلى مجموعتين احدهما ضابطة والأخرى تجريبية . r- إجر اء التكافؤ بين المجموعتين ع -إجر اء الاختبار القبلي هـنطبيق البرنامج الإرشادي على المجموعة التجريبية. إجر اء الاختبار البعدي . ثانيا : مجتمع البحث Research Popylation يقصد بمجتمع البحث بأنه مجموعة من الأفراد أو الأشياء

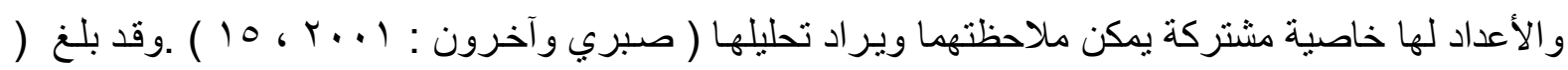
1 ا ()شاب موزعين على الكرخ و الرصافة والجدول( (1) يوضح ذلك.

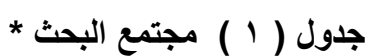

\begin{tabular}{|c|c|c|c|c|}
\hline المجموع & عدد الذكور & عدد الذكور & الموقع & اسم المنطقة \\
\hline $11 \varepsilon$ & $r \varepsilon$ & $\Lambda$. & r- الرصافة & بغذاد \\
\hline vi & rr & $r q$ & P-1 الكرخ P & بغذاد \\
\hline 110 & 79 & 119 & \multicolumn{2}{|c|}{ المجموع } \\
\hline
\end{tabular}

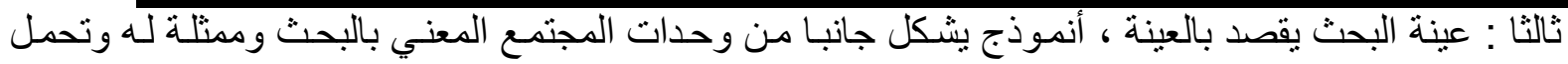

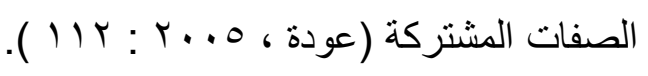
أ-عينة البناء: بلغت عينة البناء ( . . ع) شاب عاطلين عن العمل في محافظة بغداد اختيروا بطريقة عشو ائية في

$$
\text { جانب الرصافة وجانب الكرخ. و والجدول (r) يوضح ذلك }
$$

جدول ( r) حجم عينة بناء مقياس قلق البطالة

\begin{tabular}{|c|c|c|c|}
\hline المجموع & عدد الأكور & عدد الأكور & اسم المنطقة \\
\hline$r \ldots$ & $1 \ldots$ & $1 \ldots$ & الكرخ ا = r \\
\hline$r \ldots$ & $1 \ldots$ & $1 \ldots$ & الرصافة - r- r \\
\hline$\varepsilon \ldots$ & $r \ldots$ & $r \ldots$ & المجموع \\
\hline
\end{tabular}


ب- عينة التطبيق : ضمت عينة التطبيق ( • ( )شاب ممن حصلوا على أعلى الدرجات من بين الثباب الذين

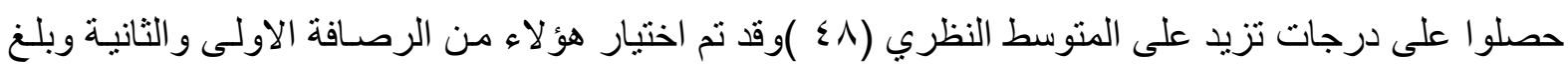

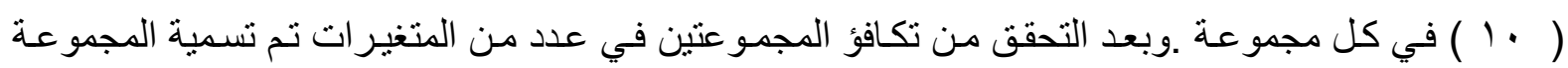
الضابطة و المجمو عة التجريبية بالأسلوب العشو ائي جدول (rّ) يوضح ذلك . جدول (rآعينة تطبيق البحث.

\begin{tabular}{|c|c|c|c|}
\hline \multirow{2}{*}{ المجموع } & الرصافة (Y) & الرصافة (1) & \multirow{2}{*}{ المجموعة } \\
\hline & ذكور & ذكور & \\
\hline 1. & $\varepsilon$ & 9 & التجريبية \\
\hline 1. & $\varepsilon$ & 7 & الضابطة \\
\hline$r$. & $\wedge$ & ir & المجموع \\
\hline
\end{tabular}

رابعا- التكافؤ بين المجموعة التجريبية والضابطة: إن تحقيق التكافؤ بين المجمو عتين التجريبية والضـابطة أمر غاية في الأهمية إذ لابد من العمل على ضبط المتغيرات الدخلية التي يمكن أن تؤثر على المتغير التابع قدر

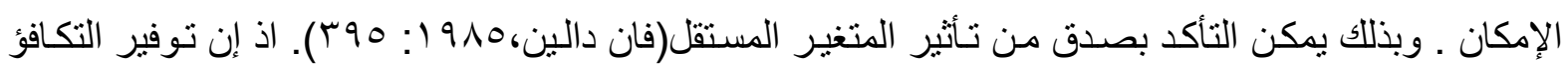
بين المجمو عات آمر ضروري لتصميم البحث, إذ تسعى الباحثة ذ إلى أن تكون مجمو عات البحث متكافئة حتى

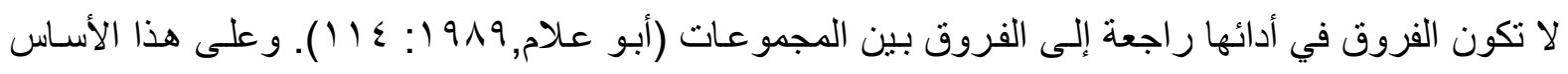

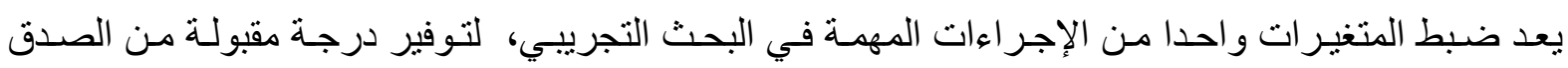
الداخلي للتصميم التجريبي بمعنى أن تمكن الباحثة من عزو معظم التباين في المتغير التابع إلى المتغير المستقل

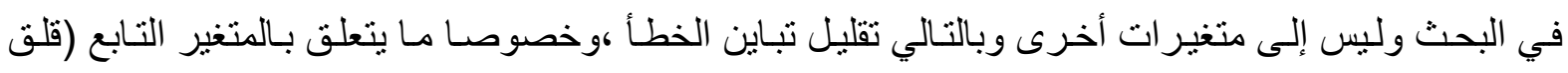
البطالة) لذا قامت الباحثة بأجر اء التكافؤ الإحصائي في هذه المتغيرات بين المجمو عتين التجريبية والضـابطة بائة وكالآتي :

أ. العمر الزمني محسوبا بالأشـهر : لأجل أجراء التكافؤ بين أفراد العينـة حددت الباحثة العمر الزمني

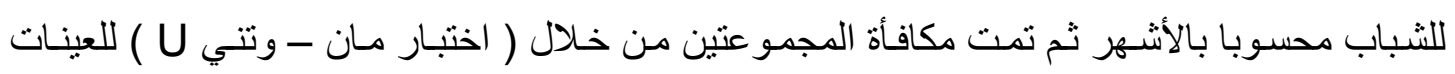

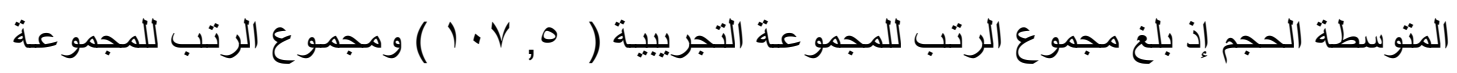

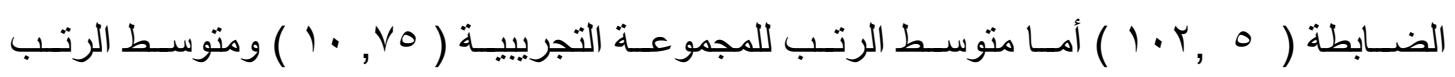

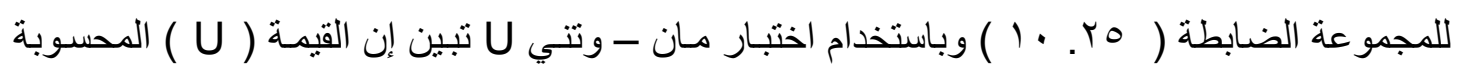
( المجموعتين التجرييية والضابطة في متغير العمر والجدول (ع) يوضح ذلك

\begin{tabular}{|c|c|c|c|c|c|c|c|}
\hline \multicolumn{8}{|c|}{ جدول (؛ ) التكافؤ في متغير العمر بين المجموعة التجريبية والمجموعة الضابطة } \\
\hline مستوي & \multicolumn{2}{|c|}{ قيمة مان وتني* } & \multirow[t]{2}{*}{ متوسط الرتب } & \multirow[t]{2}{*}{ مجموع الرتب } & \multirow[t]{2}{*}{ العدد } & \multirow[t]{2}{*}{ المجموعة } & \multirow[t]{2}{*}{ المتغير } \\
\hline., .0 & الجدولية & المحسوبة & & & & & \\
\hline
\end{tabular}




\begin{tabular}{|c|c|c|c|c|c|c|c|}
\hline \multirow[t]{2}{*}{ غير دالة } & $r r$ & $\varepsilon V, 0$ & $1 \cdot, v 0$ & $1 . V, 0$ & 1. & التجريبية & \multirow{2}{*}{ الزالثمنير } \\
\hline & & & $1 \cdot, r 0$ & $1, r, 0$ & 1. & الضابطة & \\
\hline
\end{tabular}

*قيمة مان وتتي الجد ولية تساوي بr عند مستوى 0 . , •في الاختبار ذي نهايتين.

ب.التحصيل الدراسي للأب: من أجل تكافؤ المجمو عتين ( التجريبية والضـابطة في متغير تحصيل الأب تم توزيع مستويات تحصيل الآباء الدر اسي لأفراد عينة البحث إلى أربعة مستويات( ابتدائيسة ، متوسطة ، إعداديـة , جامعية ) ولمعرفة فيما إذا كانت توجد فروق ذات دلالة إحصـائية بين المجمو عتين التجريبية و الضـابطة من

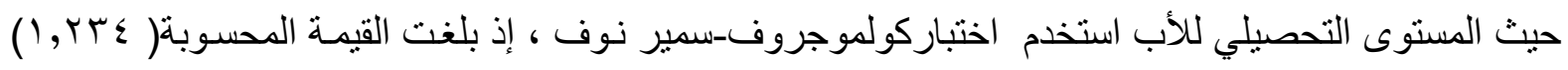
درجة وهي أصغر من القيمة الجد وليـة ( جr, 1 ) وبمستوى دلالة ( 0. , • ) و عليه لا نوجد فروق ذات دلالة إحصائية بين المجمو عتين من حيث مستوى تحصيل الآبـاء ، أي أن المجموعتين متكافئتان في تحصيل الأب

وكما موضح في جدول (0)

\begin{tabular}{|c|c|c|c|c|c|c|c|c|c|}
\hline & نشابطة & إلمجموعة & وعة التجري & لب بين الد & ل الار اسي & تغير تحص & 015 & دول & \\
\hline مستوي & \multicolumn{2}{|c|}{ قيمة kمير نوف* } & \multicolumn{4}{|c|}{ التحصيل الاراسي للاب } & \multirow[t]{2}{*}{ العدد } & \multirow[t]{2}{*}{ المجموعة } & \multirow[t]{2}{*}{ المتغير } \\
\hline., .0 & الجدولية & لمحسوية & بكالوريوس & إعدادية & متوسطة & ابتدائية & & & \\
\hline \multirow[t]{2}{*}{ غير دالة } & $1, r q$ & $1, Y \Psi \varepsilon$ & $\varepsilon$ & r & $r$ & $r$ & 1. & التجريبية & \multirow{2}{*}{ اللأبسي } \\
\hline & & & V & 1 & 1 & 1 & 1. & الضابطة & \\
\hline
\end{tabular}

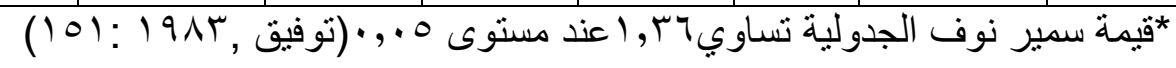

ج- التحصيل الدراسي للام : من أجل تكافؤ المجموعتين ( التجرييية والضـابطة في متغير تحصيل الأم تم توزيع مستويات تحصيل أمهات عينة البحث إلى أربعة مستويات ( ابتدائية ، متوسطة ، إعداديـة , جامعية ) ولمعرفـة فيمـا إذا كانـت توجد فـروق ذات دلالـة إحصـائية بـين المجمـوعتين التجريبيـة والضـابطة مـن حيـث المستوى التحصيلي للام استخدم اختباركولموجروف-سمير نوف ، إذ بلغت القيمة المحسوبة ( 9VV . ) درجة

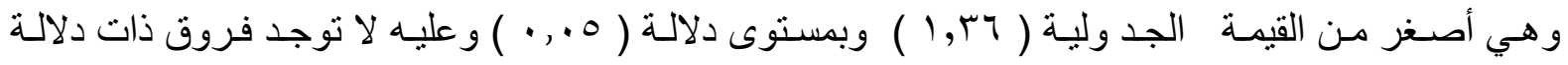
إحصائية بين المجموعتين من حيث مستوى تحصيل الام ، أي أن المجمو عتين متكافئتان في تحصيل الأم وكما

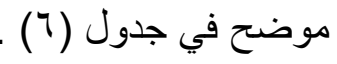

جدول (T) التكافؤ في متغير تحصيل الدراسي للام بين المجموعة التجريبية والمجموعة الضابطة

\begin{tabular}{|c|c|c|c|c|c|c|c|c|c|}
\hline \multirow{2}{*}{ مستولة الدالة } & \multicolumn{2}{|c|}{ قيمة k سميرنوف* } & \multicolumn{4}{|c|}{ التحصيل الدراسي للام } & \multirow[t]{2}{*}{ العدد } & \multirow[t]{2}{*}{ المجموعة } & \multirow[t]{2}{*}{ المتغير } \\
\hline & الجد ولية & المحسوية & بكالوريوس & إعدادية & متوسطة & ابتدائية & & & \\
\hline \multirow{2}{*}{ غالية } & $1, \pi 4$ & $\cdot, 9 \vee \vee$ & صفر & صفر & r & $\Lambda$ & 1. & التجريبية & \multirow{2}{*}{ للاراسي } \\
\hline & & & 1 & 1 & $\xi$ & $\varepsilon$ & 1. & الضابطة & \\
\hline
\end{tabular}


*قيمة سمير نوف الجد ولية تساوي بس, اعند مستوى 0., ,

د- تكافؤ الاختبار القبلي(قلق البطالة ) : لأجل إجراء التكافؤ بين أفراد العينة في متغير الاختبار القبلي(قلق

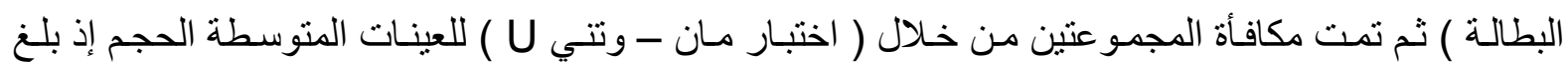
مجموع الرتب للمجمو عة التجريبية(0 , • (1) ومجموع الرتب للمجموعة الضابطة( 0 ,99) أما متوسط الرتب للمجمو عة التجريبية ( 0 . , 11) ومتوسط الرتب للمجمو عة الضابطة (90 ,9 ) وباستخدام اختبار مـان - وتتي

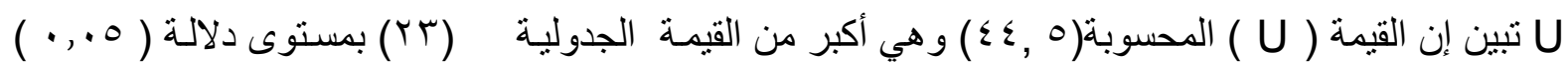
مما يدل على تكافؤ المجمو عتين التجريبية والضابطة في متغير العمر و الجدول (V) يوضح ذللك

\begin{tabular}{|c|c|c|c|c|c|c|c|}
\hline \multirow{3}{*}{ مستوى الدالاة } & \multirow{2}{*}{\multicolumn{2}{|c|}{ قيمة مان وتني" }} & \multirow{3}{*}{ متوسط الرتب } & \multirow{3}{*}{ مجموع الرتب } & \multirow{3}{*}{ العدد } & \multirow{3}{*}{ المجموعة } & \multirow{3}{*}{ المتغير } \\
\hline & & & & & & & \\
\hline & \multirow{3}{*}{$r r$} & المحسوبة & & & & & \\
\hline \multirow[t]{2}{*}{ غير دالة } & & \multirow[t]{2}{*}{$\xi \leqslant, 0$} & 11,00 & $11 ., 0$ & 1. & التجريبية & \multirow[t]{2}{*}{ قلثق البطالة } \\
\hline & & & 9,90 & 99,0 & 1. & الضابطة & \\
\hline
\end{tabular}

خامسا- أداة البحث: مقياس قلق البطالة :قامت الباحثة ببناء فقرات المقيـس على شكل مو اقف معتمدة على الاتجاه السلوكي المعرفي علمـا ان المقياس يتكون من (YV)بصيغته الاولية علمـا ان المقياس بصيغته النهائيسة يتكون (r )

صياغة الفقرات. بعد الاطلاع على الأدبيات والدر اسـات السـابقة التي تتاولت قلق البطالة ، تم صياغة فقرات

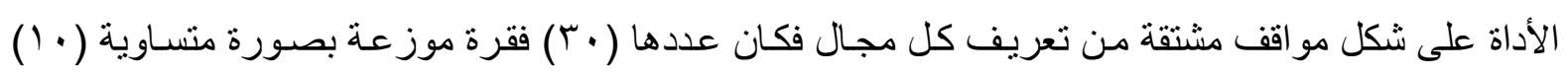

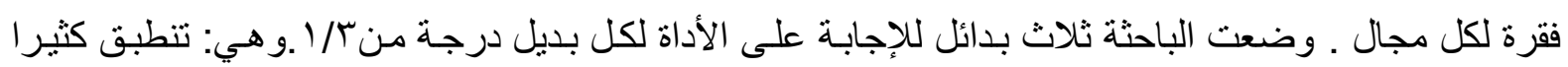
تتطبق أحياناً, ,لا تنطبق .

صلاحية الفقرات (الصدق الظاهري): تُعدّ صلاحية الفقرة من متطلبـات المقياس إذ يمكن تقييم درجـة صـلاحيّة

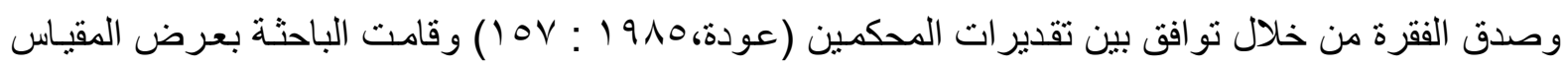
على مجمو عة من الخبر اء والمختصين في الإرشـاد النفسي و علم النفس والبالغ عددهم(· (ب)خبير ملحق رقم (Y) للتحقق من الصدق الظاهري للاداة والحكم على ملائمسة المقياس لقياس مـا وضـع من اجله, ولعينـة البحث وفعالية البدائل مع اقتر اح التعديل المناسب في حال كونها غير واضحة المعنى ووضعت الباحثة أمام كل فقرة ثلاثة بدائل (صالحة ,غير صالحة ,التعديل )

جدول(^ ) نسبة اتفاق الخبراء حول فقرات المقياس

\begin{tabular}{|c|c|c|c|c|c|}
\hline عالندائية اتل & التعديل & 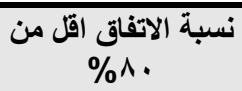 & 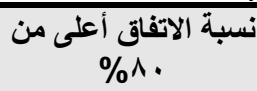 & عدد الفقرات & المجال \\
\hline$\wedge$ & $T$ & 1 & $\wedge$ & 9 & 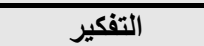 \\
\hline$\Lambda$ & $T$ & 1 & $\Lambda$ & 9 & الحالة المزاجية \\
\hline$\wedge$ & 1 & 1 & $\Lambda$ & 9 & الجوانب الجسمية \\
\hline$r \leq$ & $r$ & $\bar{r}$ & $r \varepsilon$ & $\overline{T V}$ & المجموع \\
\hline
\end{tabular}


Item-Analytic Statistics التحليل الإحصائي للفقرات (عينة البناء) يشير (Ebel, 19rr) إلى أن الهفف من تحليل الفقرات إحصائياً هو الإبقاء على الفقرات الجيدة في المقياس

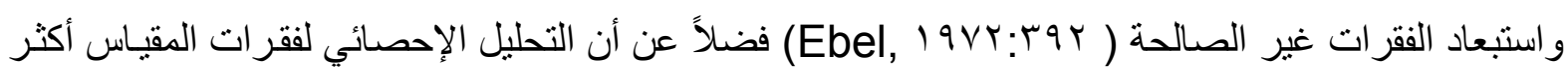

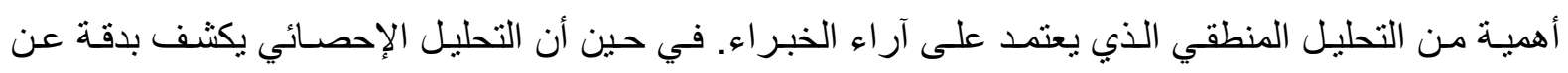

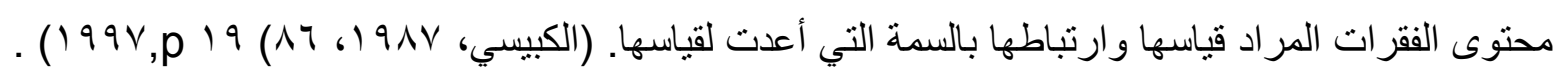
القوة التميزية للفقرات:Item- Discrimination ؛ يقصد بالقوة التميزية مدى قدرة فقرات المقياس على التى

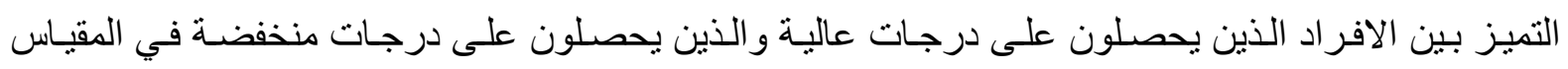

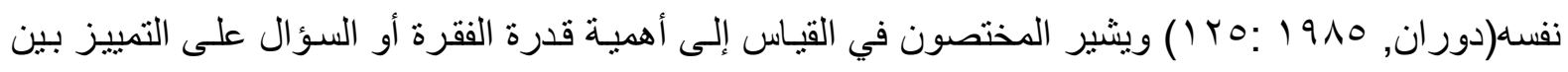

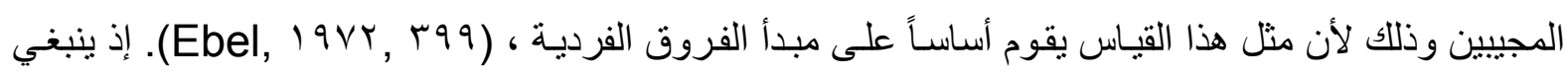

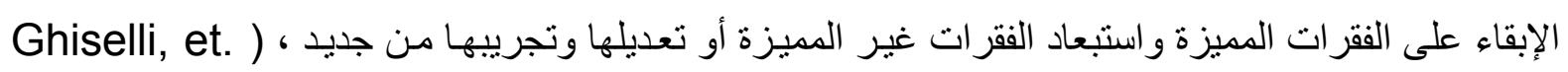
(al, 191), $\leqslant r)$

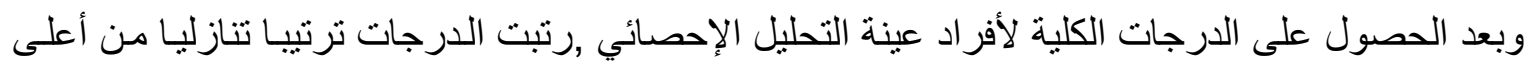

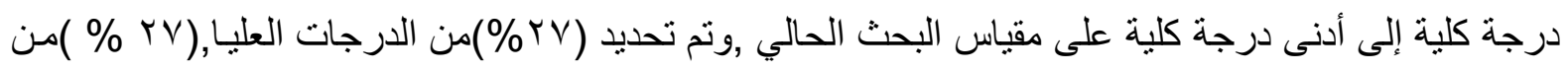

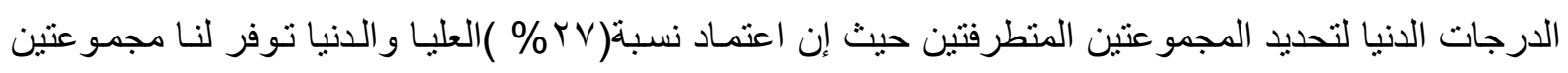

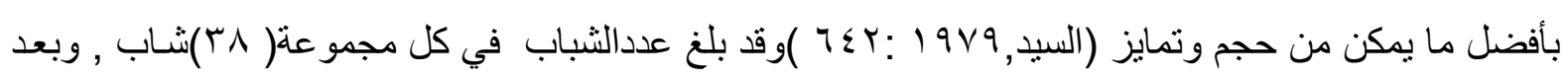

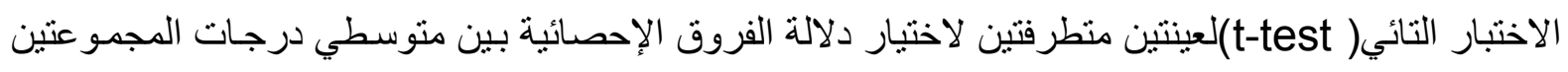

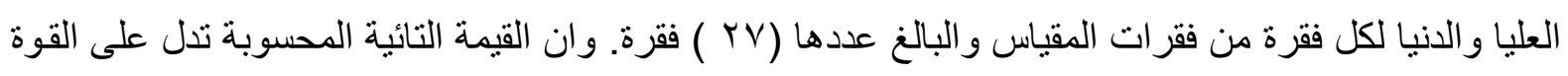

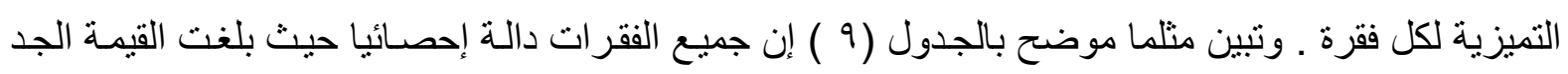

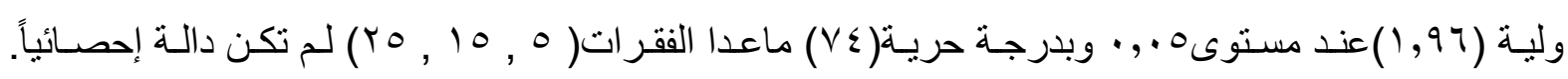

وجدول (9) وليوضح ذللك

جدول( 9 ) ) القوة التميزية لفقرات مقياس قلق البطالة

\begin{tabular}{|c|c|c|c|c|c|}
\hline \multirow{2}{*}{ القيمسو التائية } & \multicolumn{2}{|c|}{ المجموعة الدنيا } & \multicolumn{2}{|c|}{ المجموعة العليا } & \multirow[t]{2}{*}{ الفقرات } \\
\hline & الاتحراف لمعياري & الوسط الحسابي & الانحراف المعياري & الوسط الحسابي & \\
\hline$r, r \wedge I$ & $\cdot, \wedge 9 \leqslant 11$ & $1, \wedge q \leqslant V$ & $\cdot, \vee Y \otimes \leqslant \Lambda$ & r,OYTr & 1 \\
\hline r,Tro & .,AVOYY & $r, 1 T 19$ & ., マ१५१४ & $r, O V \wedge q$ & $r$ \\
\hline$r, q \wedge 1$ & דודוד & $1, q \vee r V$ &., $09 \leqslant 00$ & $r, r q \leq V$ & $r$ \\
\hline \&, & $\cdot, \wedge \ldots$. Or & $r, 1 \Lambda \leqslant r$ & ., Y৭Y人४ & $r, \Lambda / 0 \wedge$ & $\xi$ \\
\hline$r, r \wedge q$ & $\cdot, \wedge \wedge$, . & $r, r \neg \wedge \varepsilon$ &., $09 Y 10$ & $1, q \vee r v$ & 0 \\
\hline 0,010 & $\cdot, \wedge \Delta 0 \cdot \vee$ & $1, \wedge \leq Y 1$ & ., ६०97। & $r, V 1 \cdot 0$ & 7 \\
\hline$r, 7 r q$ &., 9794. & $1,9 Y 11$ &.,$\vee \backslash 4 \square$ & Y,7TוT & V \\
\hline $0, \sum V Y$ &., $790 \leqslant \leqslant$ & $1,9 \leq V \leq$ &., $00 \leqslant \mu 1$ & Y,V Y४A & $\Lambda$ \\
\hline$\theta, \vee \wedge \wedge$ & .94717 & $1, q \vee r v$ &.$\{0971$ & $r, v) \cdot 0$ & 9 \\
\hline $0, Y \otimes q$ & 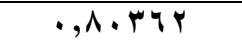 & $r, . \Delta Y T$ & 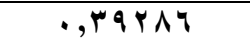 & $r, \wedge / 0 \wedge$ & 1. \\
\hline Y,TVq & ., V१৭Y० & $1, q \leq V \leq$ & $.0 \wedge 91 \xi$ & $Y, \Gamma q \Lambda \varepsilon$ & 11 \\
\hline$\varepsilon, 919$ & . & $1, \vee 1,0$ &.,$T \leqslant 0 . \varepsilon$ & $r, 00 Y T$ & Ir \\
\hline $1 ., 7 \vee 9$ &., $0.7 \cdot 1$ & 1,OYTr & ., ะ०9४। & $r, V I . \theta$ & 14 \\
\hline
\end{tabular}




\begin{tabular}{|c|c|c|c|c|c|}
\hline $0, \leqslant \leqslant 7$ & $\cdot, \vee 9940$ & $r, . \otimes r q$ & $\cdot, r q \vee \wedge q$ & $\uparrow, \wedge \backslash \bullet \wedge$ & $1 \varepsilon$ \\
\hline $1, .94$ & ., v०rq. & $r, \cdot r q r$ & $\cdot, \varepsilon V \leqslant \wedge r$ & $1, \wedge \neg \wedge \leqslant \wedge$ & 10 \\
\hline $0, r Y q$ & $\cdot, \vee \leqslant 1 \leqslant \Lambda$ & $1, \wedge ษ \wedge \varepsilon$ &., $0 T \leq .0$ & $r, 7 \circ \vee q$ & 17 \\
\hline $0, \cdot \wedge r$ & $\cdot, \Lambda \cdot M q r$ & $1,9 \leq \vee \leq$ &., 80971 & $r, V 1.0$ & IV \\
\hline$r, 701$ & $\cdot, 911 \wedge r$ & $r, \cdot \vee \wedge q$ & $\cdot, V Y \backslash 0 \leq$ & $r, \diamond \vee \wedge q$ & 11 \\
\hline$\varepsilon, .99$ &.,$\vee 141$. & $r, \cdot r q r$ & 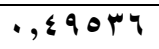 & $r, r .0 r$ & 19 \\
\hline$\vee, r \leq \Lambda$ & $\cdot, \neg \vee \wedge \wedge \wedge$ & $1, \Lambda \leq Y 1$ & ., & $r, \vee \wedge 90$ & $r$. \\
\hline r,r &.,$\vee 171$. & $r, \cdot r q r$ &.,$\leq 70 . \leq$ & Y,OOY & YI \\
\hline Y,А & $\cdot, \wedge \leq r \vee V$ & $1, \wedge \curlyvee \wedge \varepsilon$ & $\cdot, v \otimes v \leq q$ & $r, r q \leq V$ & YY \\
\hline$V, \leqslant 70$ &., $0 \leq \mid r Y$ & 1,7117 & $\cdot, 09 \leq 00$ & $r, 7.0 r$ & $r \mu$ \\
\hline$\varepsilon, 90 \leqslant$ & 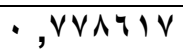 & 1, 1, &.,$T \leq Y Y \wedge$ & $Y, \odot \vee \wedge q$ & Y $\varepsilon$ \\
\hline$Y, Y V \varepsilon$ & $\cdot, 7 \vee \leq 7 \wedge$ & $r, r \checkmark \wedge \varepsilon$ &., 74717 & $r, \cdot r q r$ & ro \\
\hline $0, \mu \Psi \varepsilon$ & $\cdot, \wedge \wedge \neg 1 \%$ & $1, \wedge \leq Y 1$ & $\cdot, 0 \wedge 9 \vee \leq$ & Y,VITY & Y \\
\hline$\Lambda, \Lambda \backslash Y$ & $\cdot, 7 \leq \leq \leq 9$ & $1,1 \vee 44$ & 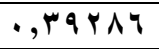 & $Y, \Lambda \backslash \bullet \wedge$ & $r V$ \\
\hline
\end{tabular}

صدق الفقرات (الاتسـاق الـاخلي) Item-Inerral Consistuncy: يعد صـدق الفقرة مـن المؤشـرات المهمة التي تكثف كون الفقرة قادرة على قياس مـا يقيسـه الاختبار أو المقياس، و الذي يحسب عـادة كما تشير

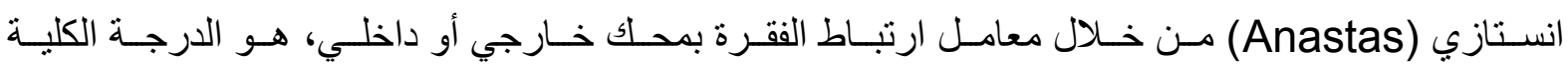

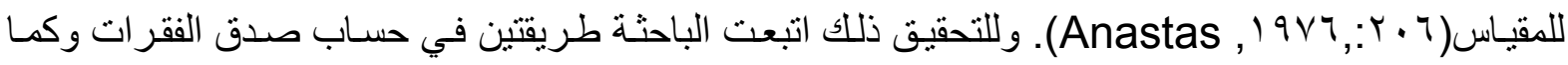

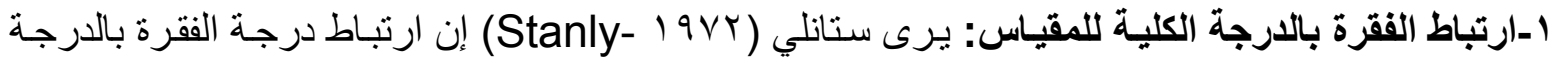
الكلية للمقياس تعني أن الفقرة تقيس نفس المفهوم الذي تقيسه الدرجة الكلية (Stanely and Hopkins)

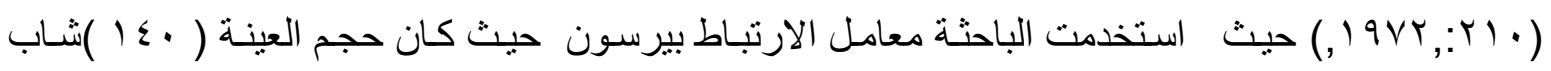

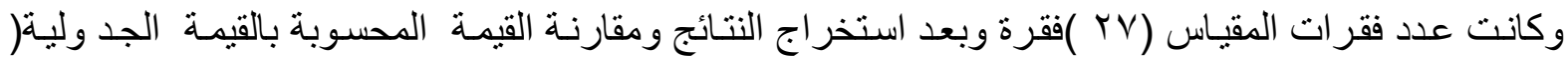

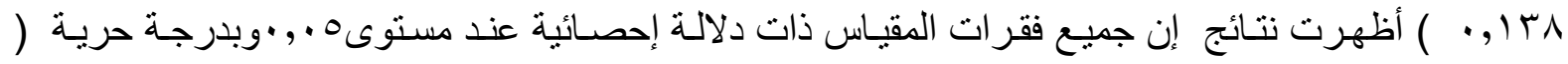

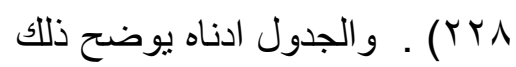

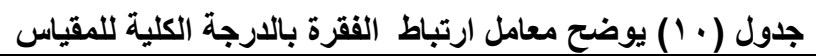

\begin{tabular}{|c|c|c|c|}
\hline معامل ارتباط الفقرة & رقم الفقرة & معامل ارتباط الفقرة & رقم الفقرة \\
\hline$\cdot, \cdot \mu_{1}$ & 10 & $\cdot, \leqslant \Psi V$ & 1 \\
\hline$\cdot, r \cdot r$ & 17 & $\cdot, r v i$ & $r$ \\
\hline$\cdot, r M I$ & IV & $\cdot, r \cdot r$ & $r$ \\
\hline$\cdot, r \otimes 0$ & 11 & $\cdot, \leqslant \mu$. & $\varepsilon$ \\
\hline$\cdot, Y q \vee$ & 19 & $\cdot, \cdot r q$ & 0 \\
\hline$\cdot, \leqslant 0 \leqslant$ & $r \cdot$ & $\cdot, \leqslant 19$ & 7 \\
\hline$\cdot, \varepsilon \Psi \varepsilon$ & YI & $\cdot, \leqslant Y \wedge$ & $\mathrm{V}$ \\
\hline$\cdot, Y Y \varepsilon$ & rr & $\cdot, r 4 \leq$ & $\Lambda$ \\
\hline$\cdot, \leqslant \Lambda$. & rr & $\cdot, \mu, \mu$ & 9 \\
\hline$\cdot, \leqslant 9 \leqslant$ & Y $\varepsilon$ &., 0.0 & 1. \\
\hline., 0 & ro & $\cdot,+19$ & 11 \\
\hline$\cdot, r \circ q$ & rq & $\cdot, r q q$ & Ir \\
\hline \multirow[t]{2}{*}{., $0 \vee 7$} & rV &., $09 \wedge$ & $1 T$ \\
\hline & & $\cdot, \leqslant 91$ & $1 \varepsilon$ \\
\hline
\end{tabular}


*القيمة الجدولية人 r ا , • عند مستوى دلالةه . , .ودرجة حريةمبr

r- ارتباط الفقرة بالمجال الذي تتنمي إلية: المجال الأول /التفكير و الانشغال الذهني - الي

حجم العينة ( • ع ( )عدد فقرات المجال (9) وبعد استخر اج النتائج ومقارنة القيمة المحسوبة بالقيمة الجد وليةة(

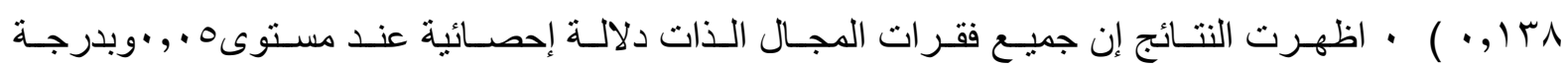

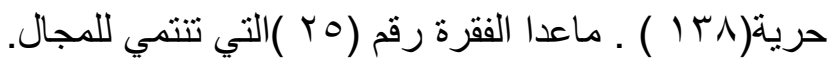
المجال الثاني/ الحالة المزاجية (التوتر والعصبية والمخاوف ).

حجم العينة ( • ع ( )عدد فقرات المجال ( 9 ) وبعد استخر اج النتائج ومقارنـة القيمة المحسوبة بالقيمة الجدوليـة(

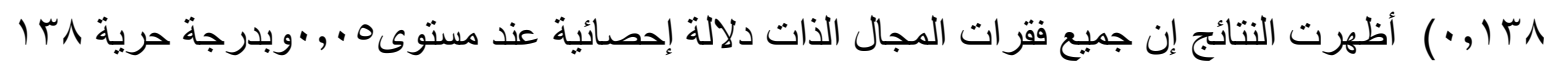
المجال الثالث/الجوانب الجسمية و البدنية .

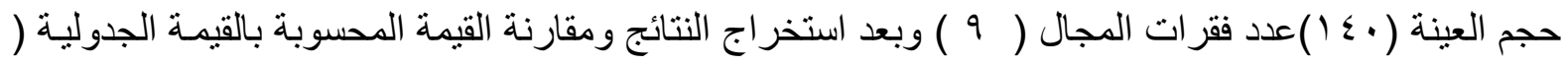

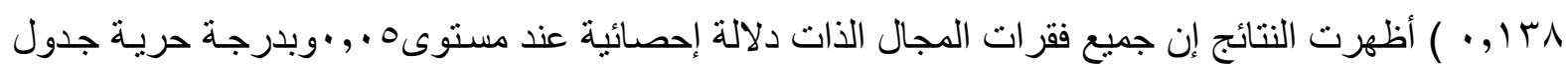
ماعدا الفقرة رقم (1') لم تكن ذو دلالة إحصائية جدول رقم ( 11 ) ) ارتباط الفقرة بالدرجة الكلية للمجال

\begin{tabular}{|c|c|c|c|c|}
\hline قيم معامل ارتباط & أرقام الفقرات & عدد الفقرات & المجال & ر قم المجال \\
\hline$\cdot, \Delta \wedge r$ & 1 & \multirow[t]{9}{*}{9} & & \multirow[t]{9}{*}{1} \\
\hline$\cdot, \varepsilon \wedge \varepsilon$ & $\varepsilon$ & & & \\
\hline., $0 \leq 0$ & $\mathrm{~V}$ & & & \\
\hline$\cdot, \leqslant \vee \wedge$ & 1. & & & \\
\hline., 00. & ir & & & \\
\hline$\cdot, r q \wedge$ & 17 & & & \\
\hline.,$Y 7 q$ & 19 & & & \\
\hline$\cdot, r \wedge r$ & rY & & & \\
\hline,.,$- 0 \varepsilon$ & ro & & & \\
\hline
\end{tabular}

\begin{tabular}{|c|c|c|c|c|}
\hline قيم معامل ارتباط & أرقام الفقرات & عدد الفقرات & المجال & ر قم المجال \\
\hline.,$O \vee 0$ & $r$ & \multirow[t]{6}{*}{9} & & \multirow{6}{*}{$r$} \\
\hline דו TY, & 0 & & & \\
\hline$\cdot, O H V$ & $\Lambda$ & & & \\
\hline$\cdot, \mu q \wedge$ & 11 & & & \\
\hline.,$r r v$ & $1 \leqslant$ & & & \\
\hline$\cdot, r \wedge V$ & IV & & & \\
\hline
\end{tabular}




\begin{tabular}{|c|c|}
\hline •, rrq & $r$. \\
\hline$\cdot, \leqslant \Delta 0$ & $r T$ \\
\hline rol & YT \\
\hline
\end{tabular}

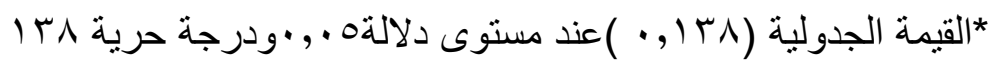
الخصائص السيكومترية للمقياس:

ا-صدق المقياس: Validity عندما يكون الاختبـار المراد تطبيقهـ يقيس الظـاهرة نفسـها التي يراد دراستهـا أو

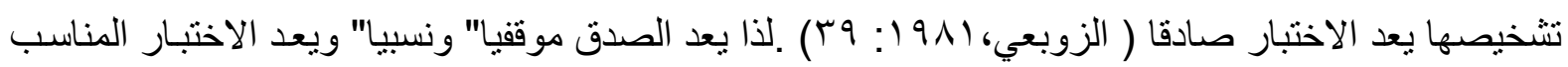
لقياس موقف ما هو الاختبار الذي يهيئ أعلى درجة من الصدق بحسب نوع الصدق المناسب للغرض الذي أعد لـد

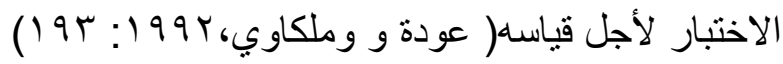
وقد تحقق الباحثة من مدى صدق الاختبار بطريقتين هي : أ.الصدق الظاهري Face Validity : يهدف هذا النوع من الصدق إلى معرفة مدى تمثيل الاختبـار للظـاهرة

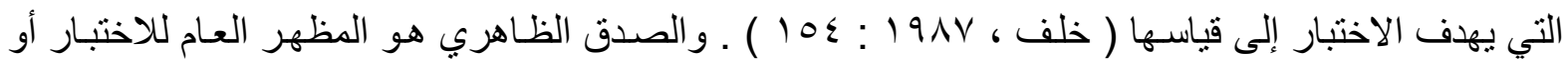
الصورة الخارجية له من حيث نوع المفردات وكيفية صياغتها ومدى وضوح هذه المفردات وتعليمات الاختبار

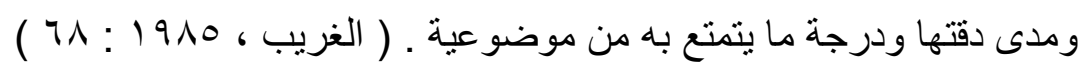
صدق البناء Construct Validity : يقصد بصدق البناء مدى قياس الاختبار لتكوين فرضية أو سمة معينة

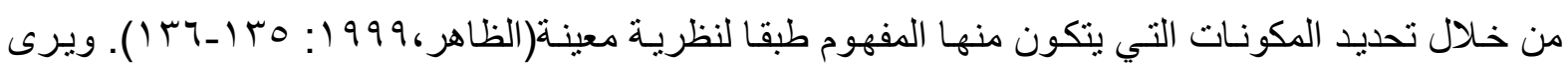
عدد كبير من المختصين في القياس التربوي و النفسي إن صدق البناء يتفق أكثر من غيره مـع جوهر مفهوم للصدق في آن الصدق هو تشبع الاختبار بالمعنى وترى ( Ebel الداخلي و هو معامل ارتباط بين كل وحدة من وحدات الاختبار والاختبار كله يستخدم لقياس مدى صـلاحية

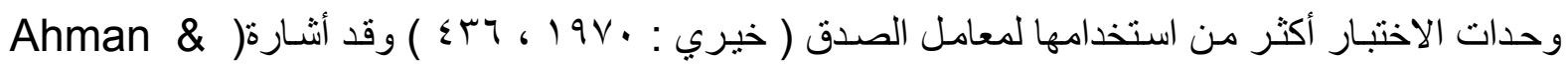
Ahman إلى إن ارتباط الفقرات بالدرجة الكلية على المقياس يعد إحدى المؤشرات على صدق البناء (Marrin

(\& Marrin; $19 \vee 0: r \backslash \wedge)$

وان مؤشـرات صـدق البنـاء الذي يسـى أحيانـاً بصـدق المفهوم أو صـدق التكـوين الفرضـي, إذ تعـد جميـع إجر اءات بناء المقياس مؤشرات لصدق البناء, كما إن القوة التمبيزية للفقرات ومعاملات صدقها من المؤشرات

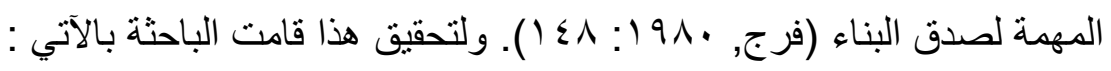

ا -ارتباط الفقرات بالدرجـة الكلية للمقياس- تعد الدرجـة الكلية للمقياس من المحكات الداخليـة لحسـاب صدق

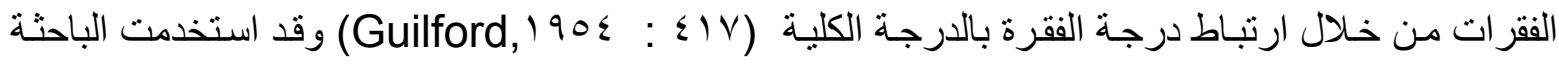

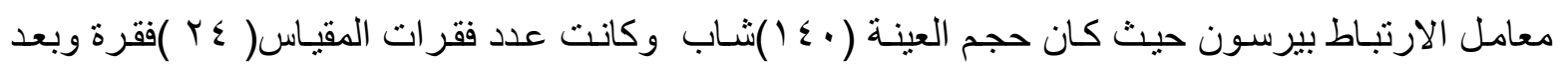


استخر اج النتائج ومقارنة القيمة المحسوبة بالقيمة الجد ولية ( ( ا , · ) أظهرت نتائج إن جميع فقرات المقياس

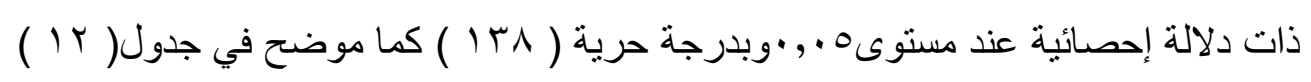

r-مصـفوفة الارتباطـات الداخليـة : تبـين مـن الجدول أدنـاه إن جميـع الارتباطـات باسـتخدام معامـل الارتبـاط بيرسون بين المجالات بعضها مع البعض الأخر جميعها دالة موجبة روهذا يثير إلى صدق البناء. جدول ( ب ا I ) مصفوفة الارتباطات بين مجالات مقياس قلق البطالة

\begin{tabular}{|c|c|c|c|}
\hline الجوانب الجسمية والبلنية & الحالة المزاجية & التفكير & مجالات قلق البطالة \\
\hline & & 1 & التفكير \\
\hline & 1 & $\cdot, 7 \vee \wedge$ & الحالة المزاجية \\
\hline 1 & $\cdot, 7 r q$ & $\cdot, 119$ & الجوانب الجسمية والبدنية \\
\hline
\end{tabular}

ثبات الاختبار Reliability : يقصد بالثبات أن يعطي الاختبار النتائج نفسـها إذا مـا أعيد تطبيقه على الأفر اد أنفسه وفي الظروف نفسها ,ويعني الثبات إن الاختبار يعطي تقديرات ثابتة,أي انه لو كرر الإجراء في عمليـة

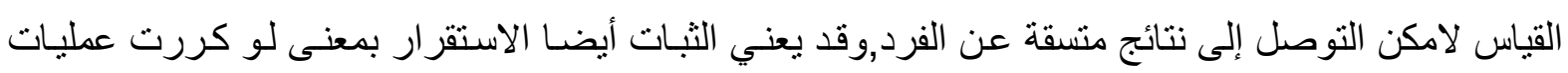

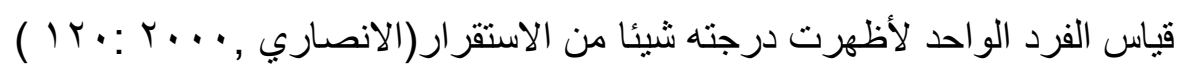
ولحساب ثبات المقياس الحالي قامت الباحثة بحسابه بطريقتين هما:

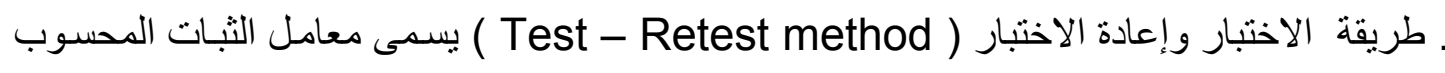

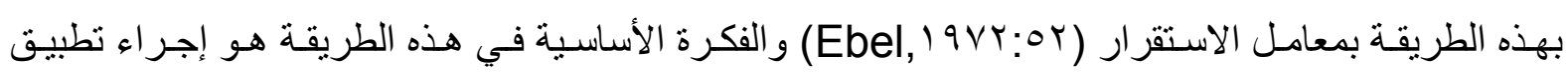
الاختبار على مجموعة من الأفراد ثم إعادة أجر اء التطبيق نفسـه على المجموعة نفسها من الأفراد في أحوال

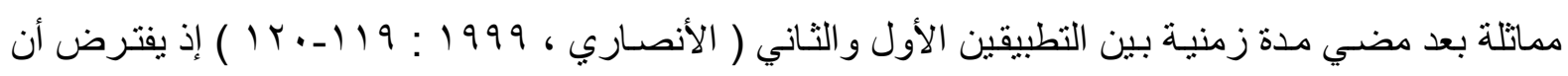
السمة ثابتة خلال المدة الزمنية بين التطبيقين الأول و الثاني،ولذلك فإن الثبات يكثف درجـة ثبات المقياس خـلال

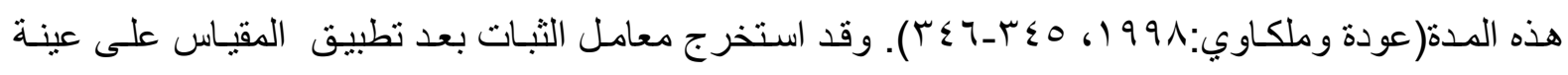
مؤلفة من ( • ع ) شاب، وبعد مرور ثناثة أسابيع من التطبيق الأولي تم اعادة التطبيق،وتعد هذه المدة مناسبة كمـا تشير(آدمز ع 9 (Adamis, إذ نم حساب معامل ارتباط بيرسون بين الدرجات على الاختبار في التطبيقين

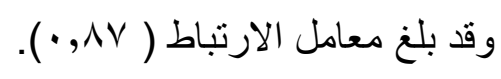

r. طريقة: الاتساق الداخلي باستخدام معادلة الفا-لكرونباخ: يطلق على هذه الطريقـة في حسـاب معامل الثبـات

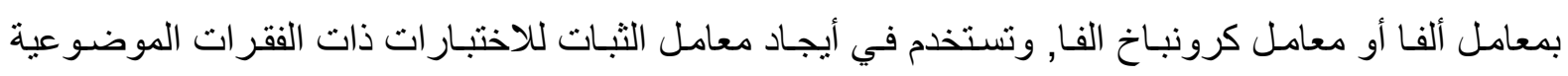

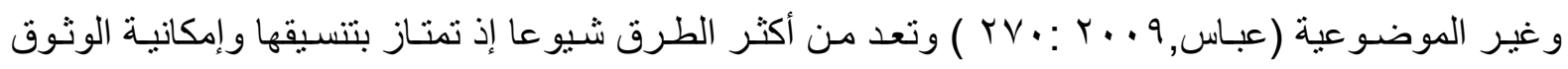

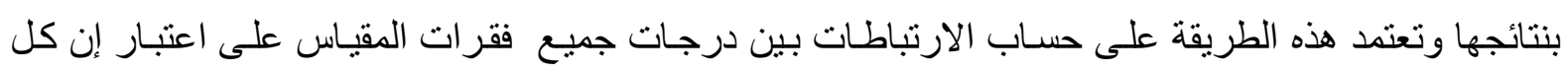
فقرة عبارة عن مقياس بذاته ويؤشر معامل الثبات على اتسـاق أداء الأفر اد أي التجانس بين فقرات المقيساس

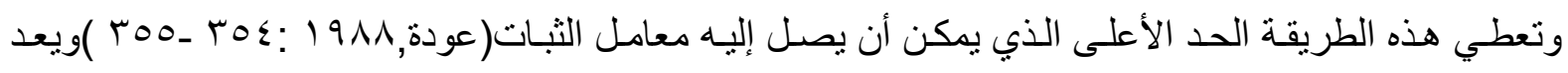
استعمال هذه المعادلة على درجات عينة الثبات كان معامل ثبات المقياس ( ع > , • ) 
التطبيق النهائي لمقياس قلق البطالة: تم تطبيق مقياس قلق البطالة بصيغة النهائية على عينة بلغت ( . . ع)شـاب

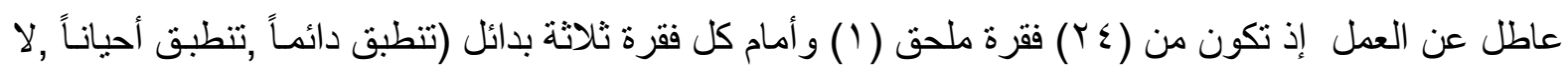

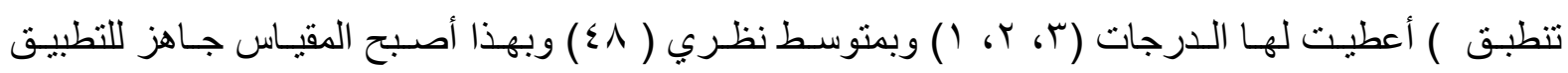

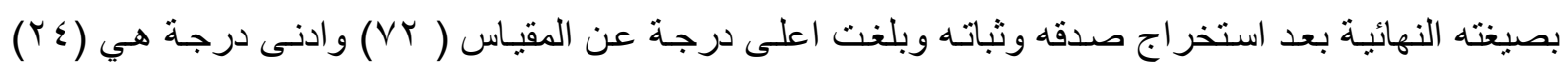

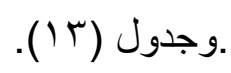

\begin{tabular}{|c|c|}
\hline \multicolumn{2}{|c|}{ جذول(r I ) المؤشرات الإحصائية لمقياس قلق البطالة } \\
\hline القيمة & المؤشر ات الاحصائية \\
\hline $71,00 \mathrm{~V}$ & الوسط الحسابي \\
\hline $4 r, \ldots$ & الوسيط \\
\hline $70, \ldots$ & المنوال \\
\hline$V, 19 r$ & الاتحر اف المعياري \\
\hline$-V \otimes 0$ & الالتواء \\
\hline $1, \ldots 1$ & التفرطح \\
\hline$\leqslant 1$ & اقل درجة \\
\hline v. & أعلى درجة \\
\hline
\end{tabular}

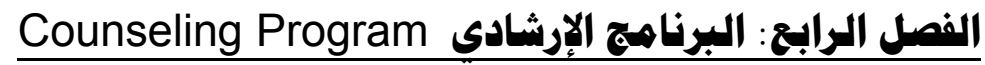

الإرشاد هو عملية مساعدة المسترشد على أن يفهم نفسـه ويوجه شخصيته لتحقيق التو افق مع بيئته بحيث يستغل إمكاناته على خير وجـه ويصبح أكثر نضجاً وأكثر قدرة على التوافق النفسي في المستقبل (الاحرش،

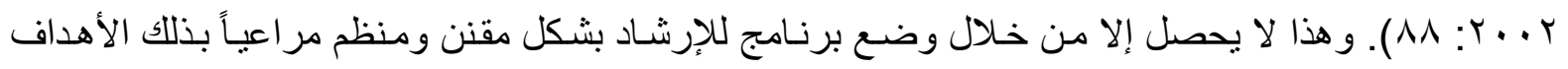

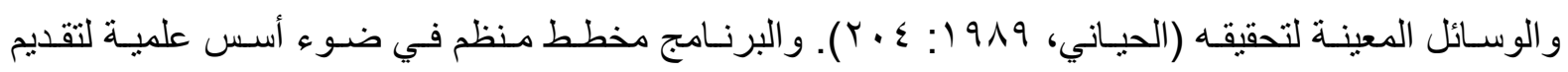

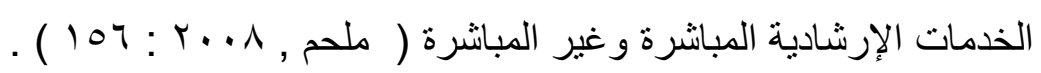

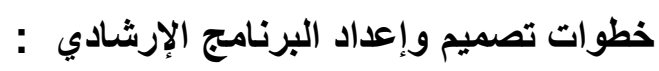
ا - تحديد السلوك الذي يريد المعالج تعديله أو علاجه .

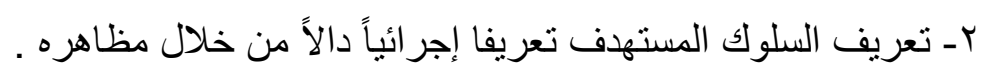

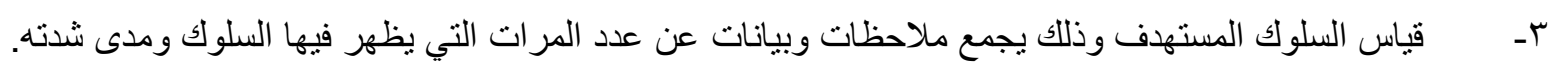
ع-تحديد الأهداف السلوكية التي ينوي المرشد تحقيقها وصياغتها بطريقة سلوكية. ــ التحليل الوظيفي للمثير ات التي تسبق وتلحق بالسـوك وتؤثر عليه ، وفيها يتم تحديد الظروف السـابقة

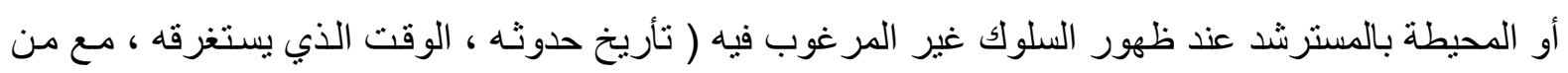
حدث ، كم مرة يحدث ، ما الذي يحدث قبل ظهور السلوك ، كيف استجاب الآخرون ، مـا المكاسب التي جناهـا التلميذ من جر اء سلوكه وأي ملاحظات ترتبط بظهور المشكلة ) .

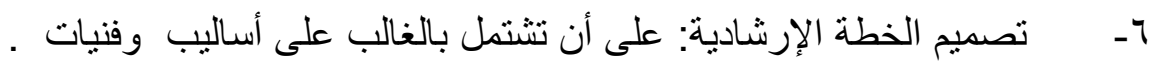

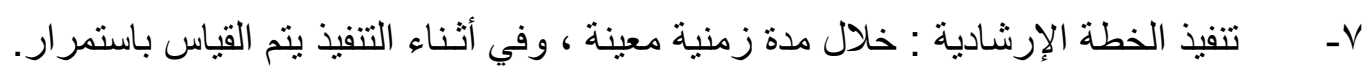

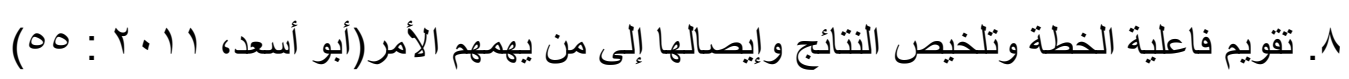
إجراءات بناء البرنامج الإرشادي أو لاً - تحديد السلوك المستهدف: 
1 - السلوك المستهدف وهو السلوك

r ـ تم تحديد أهم مظاهر السلوك قلق البطالة و المهارات الحياتية و الاجتماعية .

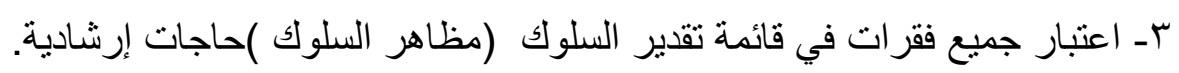

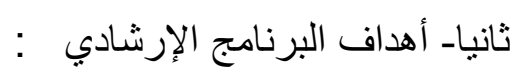
أنَّ تحديد الأهداف من الخطوات المهمة في العملية الإرشـادية إذ من شـأنه أن يقوم العمليـة الإرشـادية وتحسين

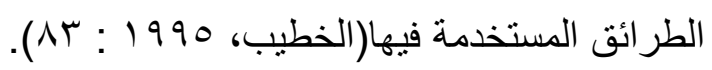
قامت الباحثة بتحديد الأهداف العامـة والخاصـة للبرنـامج الإرشـادي ولكل جلسـة على وفق الحاجـات التي تم

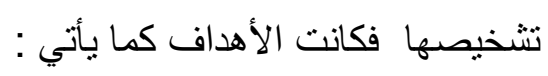
1- الهدف الرئيس من البرنامج الارشادي هو خفض السلوك قلق البطالة .

r-الأهداف الخاصة : اشتقت هذه الأهداف من الحاجات التي تم تحديدها في ضوء فقرات مقياس

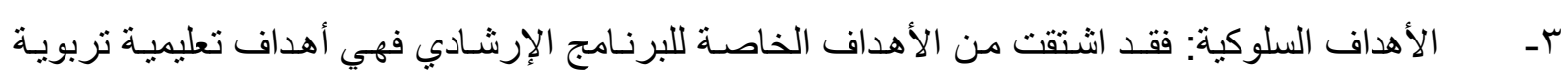
تعنى بوصف أنماط السلوك أو الأداء النهائي وتدريبهم على مهار ات التعامل مع الحياة (مهارات التعايش ). وقد الإند تم تحديد أهداف سلوكية لكل جلسة من جلسات البرنامج .

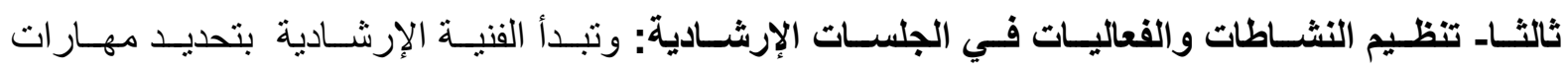
التعايش(التعامل مع الحياة ) التي يمتلكها الثخص و المهار ات التي يفتقر اليها، وتتتهي بوضـع خطة إرشـادية مناسبة للتغلب على ذلك ، و غالباً ما يدخل في هذه الفنية العلاجية فنيات علاجية عديدة: كلعب الأدوار و النمذجة

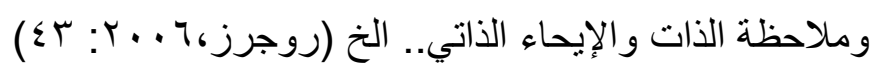
ولتحقيق ذلك وضعت مجمو عة من النشاطات و الفعاليات المختلفة في البرنامج الإرشادي على وفـق فنيـة التعامل مع الحياة وهي : 1 ـالمسو غات: وتتضمن توضيح أهمية اكتساب مهار ات التعامل مع الحياة (التعايش) و النتائج الإيجابيـة المترتبـة على إتقانها بالنسبة للفرد و الآخرين . r - تقديم التعليمات: ويقصد بها وصف المهارة للمسترشد وكيفيـة أدائها ، إضـافة إلى أهميـة اكتسابها والنتائج الايجابية المترتبة على إتقانها ، وتتمثل في كيفية تأدية السلوك من قبل المسترشد بطريقة مناسبة .

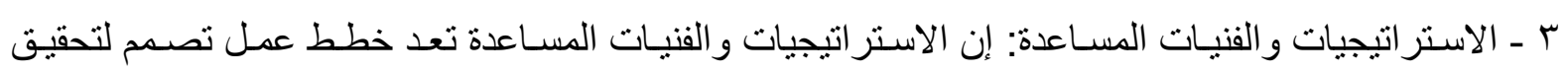
أهداف كل مسترشد وباختصار فإن الاستر اتيجيات المسـاعدة تعد بمثابـة خطة لمسـاعدة المسترشد على الانتقال نحو الأحسن ، إذ ليس هناك استر اتيجية واحدة كاملة لفهم مشكلة المسترشد و عليه فلا توجد استر اتيجية إرشـادية واحدة كاملة تناسب المو اقف جميعها ــ لذا فإن استخدام التقنيات المختلفة تسـاعد الأفر اد المختلفين في دراسـة مشكلاتهم المختلفة (العزة ، 1 . . Y : 9). ومن هذه الاستر اتيجيات و الفنيات المساعدة: ا ـالنمذجة : هي أسلوب على جانب كبير من الأهمية في البرنامج التدريبي لأنها تشبع ميل الفرد الفطري للتقليد

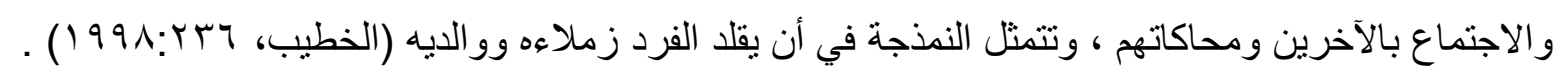


ז- لعب الدور : إن لعب الدور يوفر للفرد مجالاً للتعلم والتدريب على الحلول الممكنة في موقف معين ـ إذ إذ يتضمن الكثير من مظاهر التعلم الاجتماعي ومن أهم أركانه، أن يعبر المسترشد عن نفسـه بحريـة وصدق

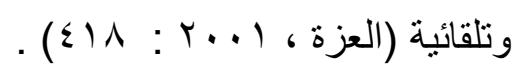

r- التعـزيز: هو أسـلوب مـنظم وجانب تطبيقي مهم في المجـال السـوكي ، ويعنـي تحديد المثيـرات الجيدة

$$
\text { للحصول على استجابات سلوكية مرغوبة به. }
$$

أـ معنوياً :- ويتمثل في الثناء و الابتسامة و الثنكر عند إتقانهم الاستجابة المرغوبة أو عند عرض مـانه ما تعلموه من

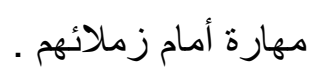

ب- مادياً :- ويتمثل في توزيع بعض الحلوى و الطعام على الثباب في نهاية كل جلسة

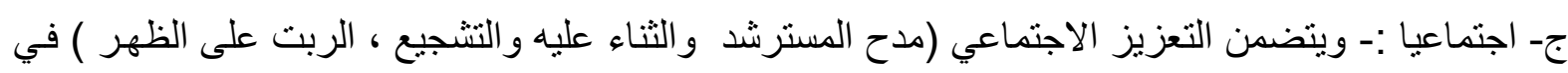
كل خطوة يتقدم فيها نحو إتقان السلوك المطلوب، واستخدام كلمات محببة ومرغوبة من قبل الثـاب مثل(ممتاز ،

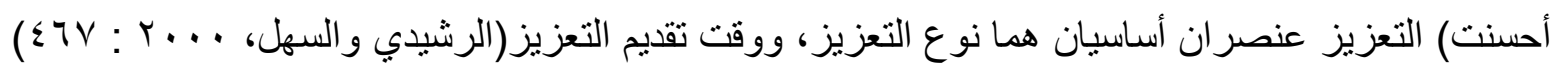
وتم مر اعاة ما يلي أثناء تطبيق البرنامج الإرشادي

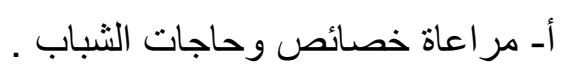

ب- المو اقف التدرييية وأنشطة الجلسات الإرشادية لمهار ات التعامل مع الحياة المستمدة من الواقع . رابعا- التدريب البيتي : Home work Assignment ويقصد به تكليف أفر اد المجموعة وتتجيعهم على تطبيق المهارة و السلوك الذي تعلموه في مو اقف حياتيـة متنوعـة وتقديم تقرير لفظي للمرشد بـللك في بدايـة

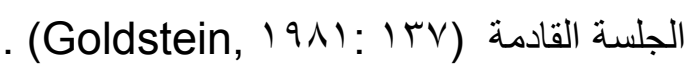
خامسا - تقويم البرنامج: يكمن الهدف الأساسي من تقويم البرنامج الإرشـادي في تصحيح وتعديل وتلافي أوجـه النقص في الأنشطة والوسائل وطر ائق تتفيذها وتتم عادةً عن طريق تحديد أسئلة والإجابة عليها عن طريق كمي

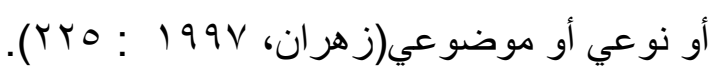
سادسا ـ صدق البرنـامج قبل تطبيق البرنـامج الإرشـادي على مجتمع البحث بعد عرضـه على مجموعة من

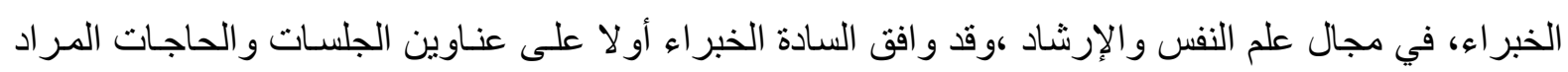

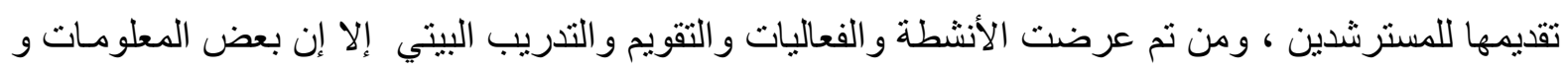
المقترحات و التعديلات قد أضيفت آو حذفت آو عدلت في البرنامج و أصبح البرنامج جاهز اً بصورته النهائية. تنفيذ البرنامج: طبق البرنامج الإرشـادي المكون من (ع () جلسـة إرشـادية بو اقع ثلاث جلسـات في الأسبوع و استغرقت كل جلسة (0ب) دقيقة والجدول (ع () الذي يوضح موضوع الجلسات وتاريخها انعقادها.

جدول (؛ ( ) موضوع الجلسات وتاريخها انعقادها

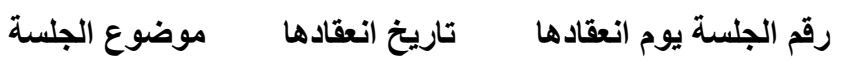

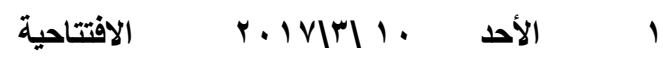

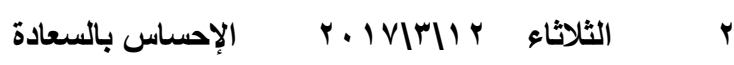

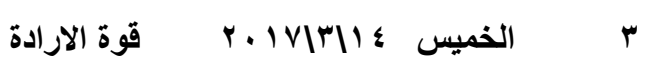




\begin{tabular}{|c|c|c|}
\hline الاهتمام الاجتماعي & r.IVITIIV & \\
\hline الجراءة والثجاعة & الثلاثاء 9 l|r|r|rr & \\
\hline التفاعل الاجتماعي & الخميس Ir|r|r|r|r & \\
\hline المشاركة الجماعية & r.IVITIY & \\
\hline الثقة بالنفس & 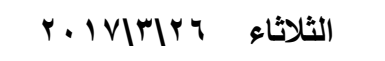 & \\
\hline الأمن النفسي & الخميس^ץ|r|V | ـ ץ & \\
\hline التعاون & $r \cdot|V| r|r|$ & 1. \\
\hline حب الآخرين & 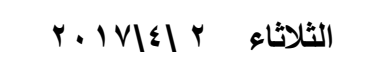 & 11 \\
\hline العلاقات الإنسانية & 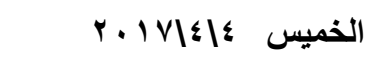 & \\
\hline التواصل الاجتماء & $r+|V| \leqslant \mid V$ & \\
\hline الختامية & 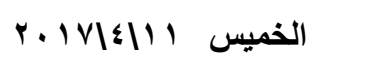 & \\
\hline
\end{tabular}

وفيما يلي عرض لجلسات البرنامج و إدارتها:

مدة الجلسة • ــ دقيقة

الجلسة الأولى (الافتتاحية )

الحاجات الأهداف السلوكية الأنشطة والفعاليات التقويم البنائي التدريب البيتي

ـالتهيؤ و التمهيد للجلسات الإرشادية.

-تعرف أفر اد المجمو عة. و على بعضهم البعض

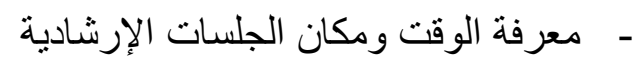

- إز الة الحواجز النفسية بين الباحثة والمجمو عة.

ـأن يتمكن المسترشدين من التعرف على المو اضيع و الأنشطة التي سوف يتم التدريب عليها.

ـ تعريف أفر اد المجمو عة بالضو ابط و التعليمات الخاصة بالجلسات الإرشادية.

- تحديد الهذف العام من البرنامج ,و النشاطات المقدمة

ـ التأكيد على ضرورة الالتزام بحضور الجلسات. - تقدم الباحثة نفسه للمجموعة الإرشادية. ـأخبار المجموعة بموضوع البرنامج والهدف منه

-تقدم الباحثة مجموعة من الأسس التي تكون لها أهمية في تتظيم سلوك أفر اد المجمو عة الإرشادية.

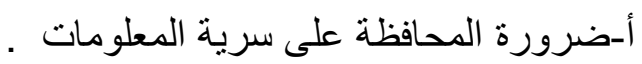

ب-التأكيد على الالتزام والحضور في المكان والزمان المخصص لانعقاد الجلسات الإرشادية. ج-تنفيذ ما يتم الاتفاق عليه وأداء التدريبات البيتية. د-لكل شاب الحق بأن يتحدث بحرية . إدارة الجلسة الإرشادية الأولى(الافتتاحية ):

اـ تقدم الباحثة (المرشـد) بتعريف نفسـة (المسترشدين) مـع إعطلـاء مـوجز عن بطاقته الثخصية وتحصيله الأكاديمي. r-تحاول الباحثة (المرشد)خلق جو من الانسجام و الآلفة و الحوار المتبادل من خلال طرح بعض الأسئلة على المسترشدين ويتم ذلك بأسلوب لطيف خالَ من التعقيد . 
عـ تشجيع الثباب (المسترشدين)على التحدث دون خوف أو خجل وذللك عن طريق فتح حوار معهم بشـان الكثير من القضـايا المتعلقة بموضوع البحث مثنل النشـاطات المفضلـة لديهم ،أي القدرات والقابليـات التي مئي

$$
\text { تجيدون ,الرسم, الرياضة }
$$

عـ إعطاء فكرة عما سيقوم به الباحثة في البرنـامج من استضـافة ضيوف و عرض أغاني و الألعاب الرياضية و المسرحيات التي ننوي القيام بها معا وتفاصيل الحفلة التي ينوي القيام بها كي يشجع (المسترشدين) للتجاوب

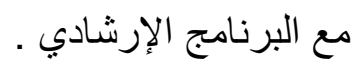
التقويم البنائي: رأي المسترشد بطريقة إدارة الجلسة الإرشادية. ومن تحديد التدريب البيتي .

\section{الفصل الخامس : :عرض النتائج وتفسيرها}

يتضمن هذا الفصل عرضـا لنتائج البحث الحسالي في ضـوء هدف البحث وفروضـه مـع مناقثـة هذه النتائج

$$
\text { هدف البحثير ها . }
$$

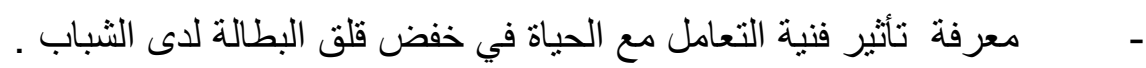

ا ـ قياس قلق البطالـة لدى الثـباب: بلـغ المتوسط الحسـي لدرجات أفراد عينة التطبيق النهائي لمقيـاس قلق البطالة (1,00V)

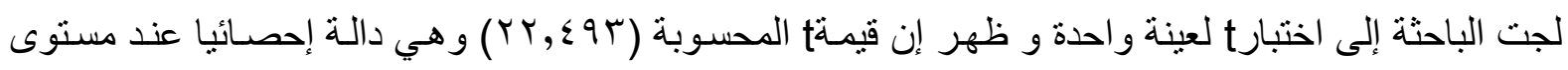
دلالة ه. . • وكما هو موضـح بالجدول (10) أدنـاه ممـا دل على إن قلق البطالـة مؤشر لدى أفراد العينـة بدلالـة

\begin{tabular}{|c|c|c|c|c|c|c|}
\hline مستوى الدلالة & قيمة الجدولية & tاقيمة tالمحسوبة & الوسط النظري & الالحياري & الوسط الحسابي & العينة \\
\hline., .0 & 1,97 & $r r, \& q r$ & $\leqslant 1$ & $V, 19 Y$ & $71,00 \mathrm{~V}$ & $1 \leqslant$. \\
\hline
\end{tabular}

إحصائية .

جلول (0 1 ) اختبار t لعينة واحدة لمقياس قلث البطالة

r. اختبار فرضيات البحث : الفرضية الأولى: لا توجد فروق ذات دلالـة إحصـائية في درجـات قلق البطالـة (للمجمو عـة الضـابطة ) في الاختبـار القبلي و البعدي. ولتحقق مـن ذلك استخدمت الباحثنة اختبـار ولكوكسن.

\begin{tabular}{|c|c|c|c|c|c|c|c|c|c|}
\hline الفرق & 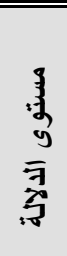 & $\begin{array}{l}\overline{7} . \\
\text { ज़े. }\end{array}$ & $\begin{array}{l}\overline{3} \\
3 \\
3 \\
3\end{array}$ & الإثارة الأقل & رتبة الفرق & القبل درجي والبعدي بلين & رجيموعة & الاخت & تألفر ادل \\
\hline \multirow{3}{*}{ 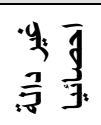 } & & \multirow{3}{*}{$\wedge$} & \multirow{3}{*}{$r V$} & & $\varepsilon, 0$ & $1-$ & $7 \varepsilon$ & 70 & 1 \\
\hline & & & & 1. & 1. & $\Lambda+$ & 71 & 7. & $r$ \\
\hline & & & & & $\varepsilon, 0$ & $1-$ & 71 & 74 & $r$ \\
\hline
\end{tabular}
و الجدول (7 ا ) يوضح ذلك.

جدول (14) قيمة اختبار و لكو كسن للمجموعة الضابطة في الاختبارين القبلي والبعدي 


\begin{tabular}{|c|c|c|c|c|c|c|}
\hline \multirow{7}{*}{$\cdot, \cdot 0$} & & $r, 0$ & $Y_{-}$ & 71 & $v$. & \{ \\
\hline & $\Lambda$ & $\Lambda$ & $r+$ & 79 & $7 \varepsilon$ & 0 \\
\hline & 9 & 9 & $0+$ & $7 \mathrm{~V}$ & $7 r$ & 7 \\
\hline & & 7,0 & , & 70 & 70 & $v$ \\
\hline & & 1 & $r_{-}$ & 7. & r & $\Lambda$ \\
\hline & & 7,0 & . & 74 & r & $q$ \\
\hline & & $r, \theta$ & $r_{-}$ & 70 & $7 V$ & 1. \\
\hline
\end{tabular}

ويتضح من الجدول أعلاه انه ليس هناك فروق ذات دلالة إحصـائية بين درجات الاختبارين (القبلي و البعدي) بالنسبة للمجموعة الضابطة حيث كانت القيمة المحسوبة YV و القيمة الجدولية 1عند مستوىه . , .

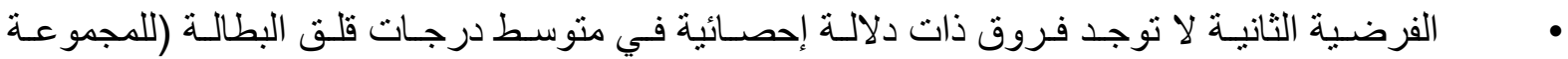
التجريبية)في الاختبار القبلي و البعدي. ولتحقيق ذلك استعملت الباحثة اختبار ولكوكسن و الجدول (V V)يوضح

جدول (V V ) قيمة مان- وتني للاختبار البعدي قلق البطالة للمجموعتين الضابطة والتجريبية

\begin{tabular}{|c|c|c|c|c|c|c|c|c|c|}
\hline دلالة الفرق & $\begin{array}{l}3 \\
3 \\
y \\
\overline{7} \\
z 3\end{array}$ & 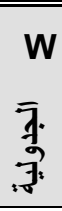 & قَيمة & الرالثبارة ذات الأقل & رالفرق & القبن & البعدي & الاختبار & تسلسل الأفراد \\
\hline \multirow{10}{*}{$\frac{\frac{7}{3}}{\sqrt[3]{3}}$} & \multirow{10}{*}{$\cdot, .0$} & \multirow{10}{*}{$\wedge$} & \multirow{10}{*}{ صفر } & لا توجد & 9 & $1 Y=$ & $\Delta V$ & 79 & 1 \\
\hline & & & & لا توجد & $r, 0$ & IV= & $\varepsilon V$ & $7 \leq$ & $r$ \\
\hline & & & & لا توجد & 0 & $10=$ & $\leqslant 0$ & 7. & $r$ \\
\hline & & & & لا توجد & 7 & $1 \leq-$ & $\sum 9$ & 74 & $\varepsilon$ \\
\hline & & & & لا توجد & $r$ & $1 \Lambda_{-}$ & $\varepsilon \wedge$ & 79 & 0 \\
\hline & & & & لا توجد & $V, 0$ & $1 \%=$ & 0. & $4 \pi$ & 7 \\
\hline & & & & لا توجد & 1. & $9-$ & or & $7 Y$ & $\mathrm{~V}$ \\
\hline & & & & لا توجد & $r, 0$ & $1 V_{-}$ & $\xi \Lambda$ & 70 & $\Lambda$ \\
\hline & & & & لا توجد & $V, 0$ & $1 \%=$ & $0 \leq$ & $7 V$ & 9 \\
\hline & & & & لا توجد & 1 & 19. & $\leq 7$ & 70 & 1. \\
\hline
\end{tabular}

الفرضية الثالثة ؛لا توجد فروق ذات دلالـة إحصـائية بين درجـات قلق البطالة لافر اد المجموعتين

(التجريبية والضابطة)بعد نطبيق البرنامج في الاختبار البعدي ,وللتحقق من ذلك استخدمت الباحثة اختبار مـانوتني لمعرفة دلالة الفروق بين المجمو عتين و الجدول رقم (1 ( )يوضح ذلك.

\begin{tabular}{|c|c|c|c|c|c|c|c|}
\hline \multirow{2}{*}{ مستوى الالالة } & \multicolumn{2}{|c|}{ قيمة مان وتني* } & \multirow[t]{2}{*}{ متوسط الرتب } & \multirow[t]{2}{*}{ مجموع الرتب } & \multirow[t]{2}{*}{ العدد } & \multirow[t]{2}{*}{ المجموعة } & \multirow[t]{2}{*}{ المتغير } \\
\hline & الجدولية & المحسوبة & & & & & \\
\hline \multirow{2}{*}{ التجريبية لصالح } & \multirow[t]{2}{*}{$r r$} & \multirow[t]{2}{*}{ صفز } & 10,0 & 100 & 1. & التجريبية & \multirow{2}{*}{ الاختبار البعدي } \\
\hline & & & $\bullet, \Lambda$ & $\theta \wedge$ & 1. & الضابطة & \\
\hline
\end{tabular}

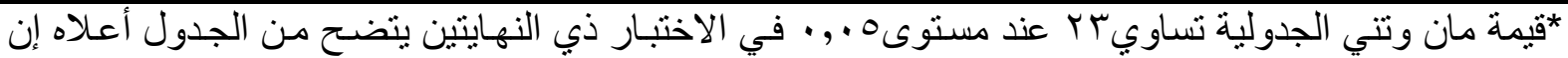
القيمة الجدولية هي اكبر من القيمـة المحسوبة ولصـالح المجموعة التجريبية وبذلك ترفض الفرضية الصفرية وتقبل الفرضية البديلة. التي تشير إلى وجود فروق بين المجموعتين (التجريبية والضابطة ).

مما يدل على إن هناك تاثير ايجابي للبرنـامج الإرشـادي في خفض قلق البطالة لدى الثباب، وتعزو الباحثة سبب ذللك إلى إن جلسات البرنامج الإرشادي بفنية التعامل مع الحياة كانت: 


$$
\begin{aligned}
& \text { 1 - شجعت الثباب على استغلال ما لديهح من طاقات إلى أقصى حد ممكن. }
\end{aligned}
$$

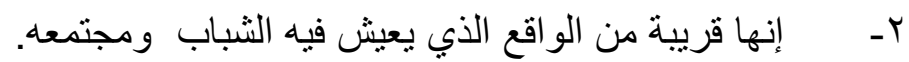

$$
\begin{aligned}
& \text { r- استخدام نماذج حية من الو اقع . }
\end{aligned}
$$

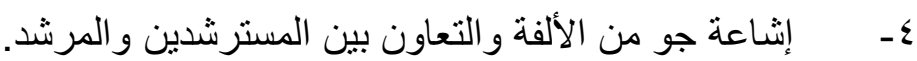

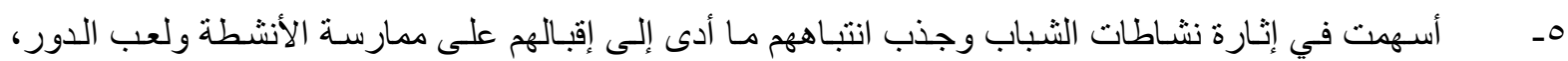
وجعلهم أكثر فاعلية في علاقاتهم مع الآخرين ، و أكثر استقلالية و الاعتماد على أنفسه في وظائف حياتهم اليومية.

$$
\text { الاسـتنتـاجـات :- في ضوء نتائج البحث ، يمكن استتناج ما يأتي :- }
$$$$
\text { ا-ضرورة التصدي للمشكلات النفسية والاجتماعية التي تواجه الثباب . }
$$

r- استثمار أقصى ما يمكن استثماره من طاقات وقدرات لتنمية مهار اته الاجتماعية وتقبله المسؤولية الاجتماعية. r- إتاحة الفرص لتعبير عن قدرته وطموحاته وممارسة هو اياته . التوصيات : استنادا إلى نتائج البحث توصي الباحثة بما يأتي : 1-الإفادة من المقياس المستخدم في البحث الحالي في در اسات مستقبلية . r-الإفادة من البرنامج الإرشادي الحالي في خفض قلق البطالة لدى الثباب .

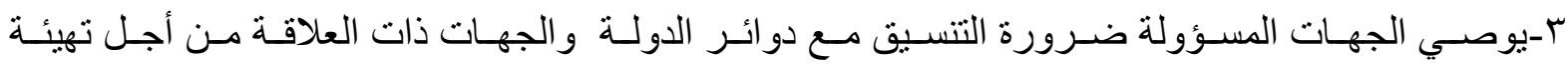
المستلزمات و التجهيزات الضرورية لعمل الثباب .

المقترحات : استكمالاً لنتائج البحث الحاليّ تقتر ح الباحثة ما يأتي:

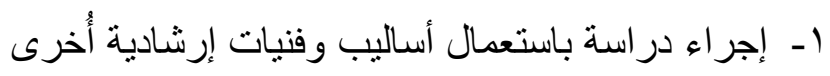

r- إجر اء دراسة تتنتاول سلوكيات أخرى غير التي تناولتها الدر اسة الحالية .

\section{المادر العربية:}

$$
\text { *القران الكريم }
$$

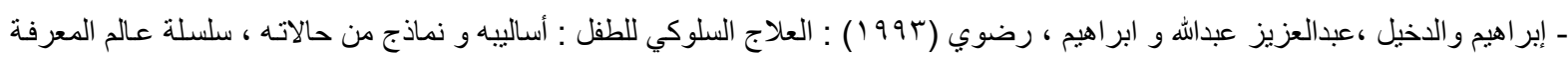

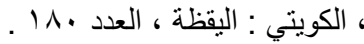

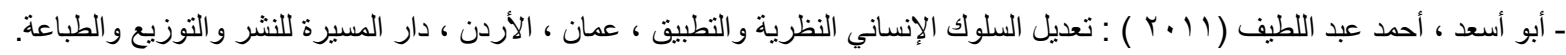
- أبو علام, رجاء محمود,(1919 (199 ): مدخل إلى مناهج البحث التربوي, مكتبة الفلاح, الكويت.

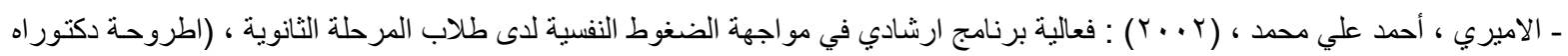

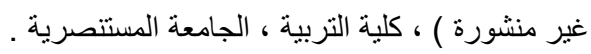
ـ الأنصاري ,بدر محمد(999 (199): قياس الثخصية ,دار الكتاب الجامعي ,الكويت. ـ البياتي، عبد الجبار نوفيق (1910 ()): التحليل الإحصائي في البحوث التربويـة والنفسية والاجتماعيةــ الطرق اللامعلمية، ط كا، مؤسسـة الكويت للتقدم العلمي - الكويت. - جاسم ، عبد السلام جودت (919 (1) : أثر العقوبة في احداث السلوك العدواني وعلاقة ذلك ببعض أسـاليب المعاملة الو الدية ، رسالة ماجستير غير منشورة ، كلية الآداب - الجامعة المستنصرية.

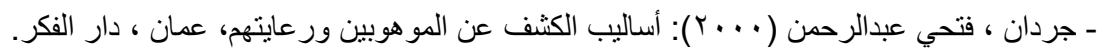


ـالجلبي ، علي ، (9V^1) : الطب النفسي الاجتماعي النظرية والتطبيق، دار المعرفة الجامعية ، الإسكندرية ، مصر.

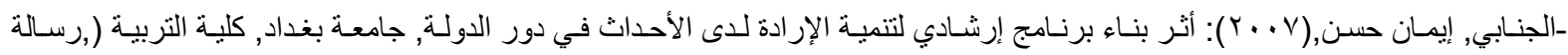

ماجستير غير منشورة). ـ الخطيب ، جمال (ب99 19) ، تعديل سلوك الأطفال دليل الآباء و المعلمين، دار الإشراق للنشر ، عمان .

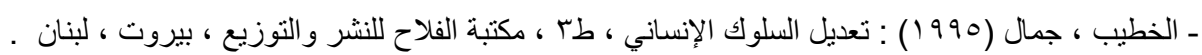

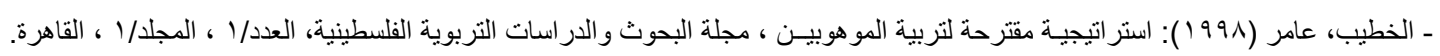

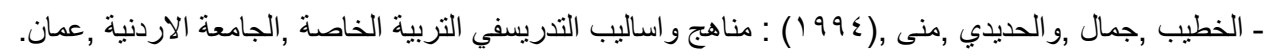

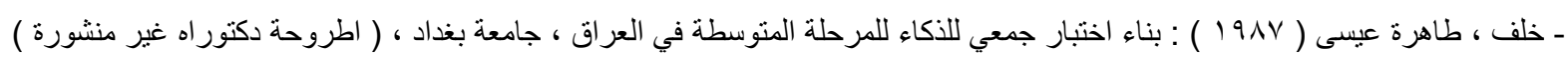

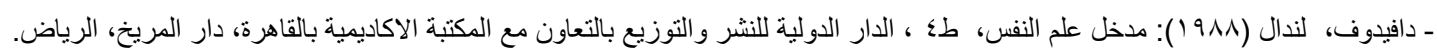

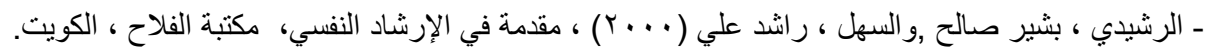

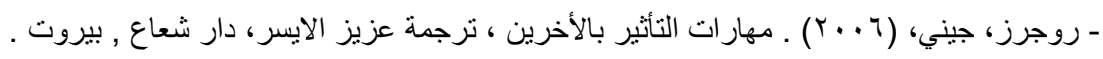

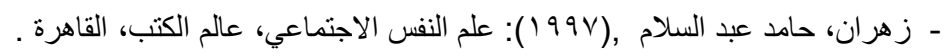

ـ شلتتر ، داون،(ب 9 ( ))، نظريات الثخصية، ترجمة الكربولي، حمدولي و القيسي، عبد الرحمن، مطبعة جامعة بغداد، بغداد.

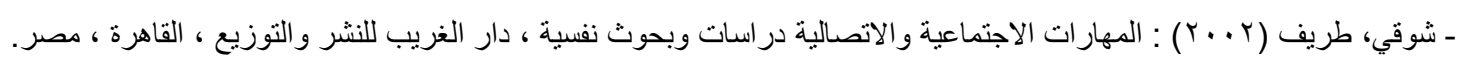

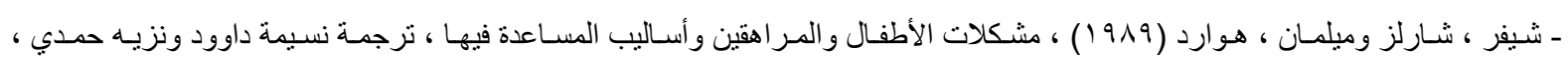
منشور ات الجامعة الاردنية، عمان ، الاردن.

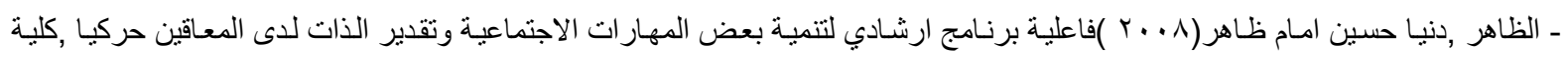
التربية ,جامعة عين الثمس ,اطروحة دكتور اه

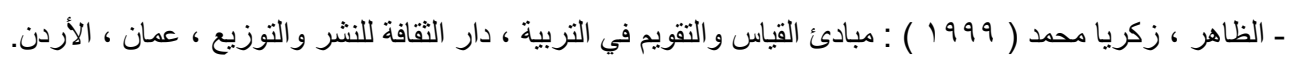

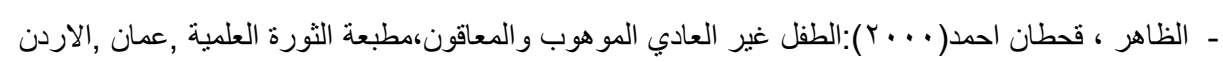

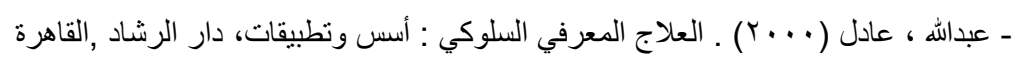

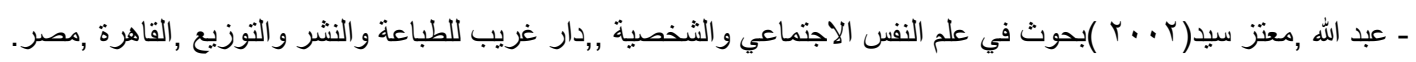
- عبد اللطيف , اذار( ( . . ) ) العلاقة بين مفهوم الذات والتكيف الاجتماعي لدى المعوقون جسديا ,رسالة ماجستير ,جامعة دمشق ,سوريا.

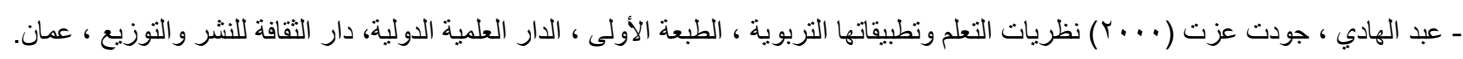

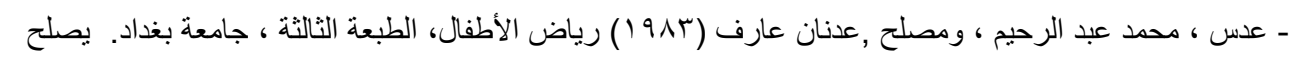

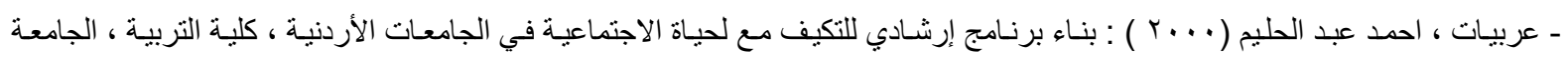
المستتصرية ، أطروحة دكتور اه غير منشورة.

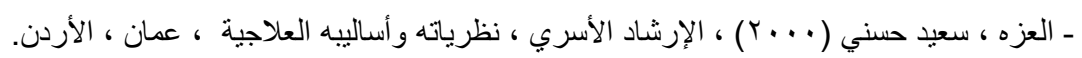

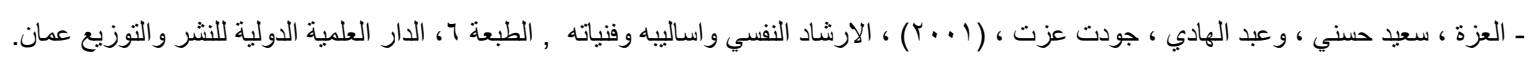

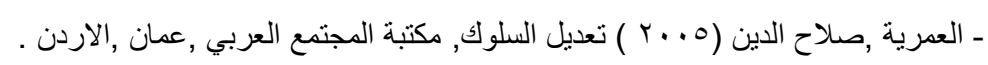

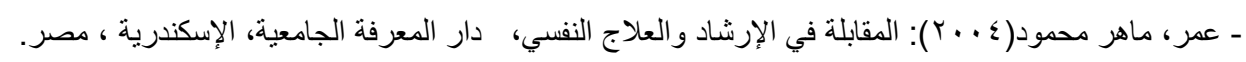

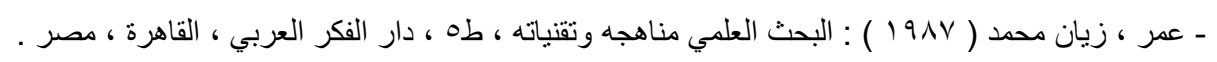

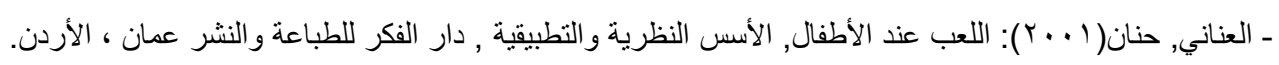

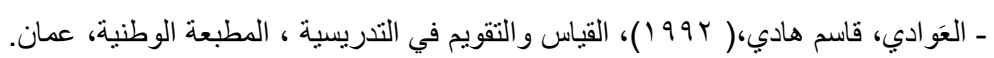

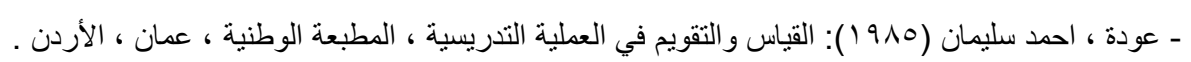

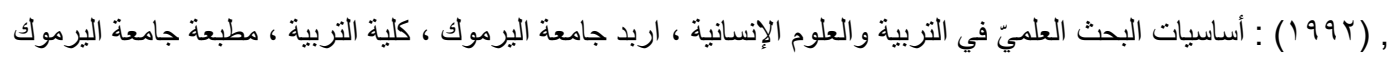

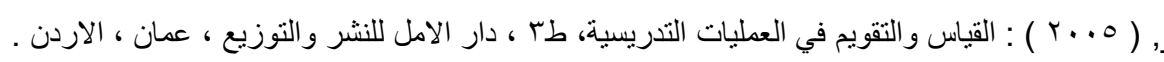

- عودة، احمد سليمان ، وملكاوي ، فتحي حسن (r99 (19) :أساسيات البحث العلمي في التربية والعلوم الإنسانية ،طץ، مكتبة الكناني, اربد,الاردن.

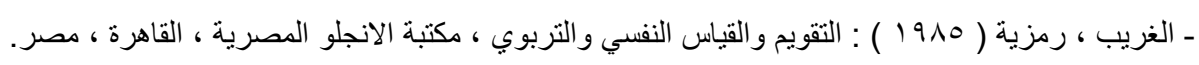

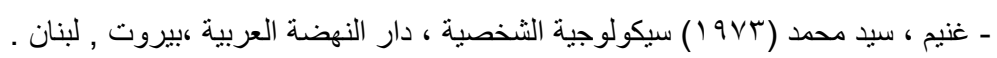
ـ فان دالين ، ديو بولدب ( •191 ) ) : مناهج البحث في التربية وعلم النفس ، ترجمة محمد نبيل نوفل ، طب ، مكتبة الانجلو المصرية ، القاهرة ، مصر. 


$$
\begin{aligned}
& \text { - فرج ، صفوت ، (191 (1) ، القياس النفسي ، دار الفكر العربي ، القاهرة. }
\end{aligned}
$$

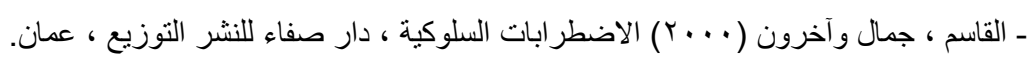

$$
\begin{aligned}
& \text { ـ القاضي، يوسف مصطفى واخرون، (1919) (الارشاد النفسي والتوجيه التربوي، طه، دار المريخ، الرياض، السعودية }
\end{aligned}
$$

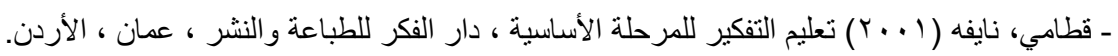

$$
\begin{aligned}
& \text { - كونجر ، بول مسن ، (7 (191) اسس الطفولة و المر اهقة، ترجمة احمد عبد العزيز سلامة ، مكتبة الفلاح، الكويت. }
\end{aligned}
$$

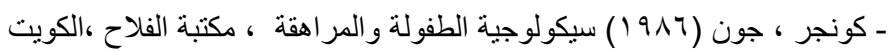

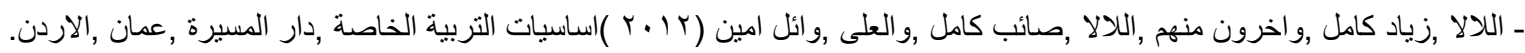

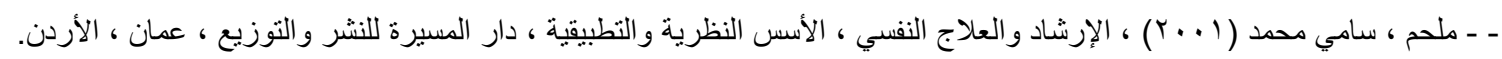
ـ ملكية ,لويس ( (99 9 ) )العلاج السلوكي وتعديل السلوك ,طץ ,دار الفكر للطباعة والنشر ,عمان ,الاردن.

ـ منصور ، محمد طلعت(9VV ( ) ):التعلم الذاتي وارتقاء الثخصية،مكتبة الانجلو المصرية ،القاهرة.

ـ هجمان، علي خالد (ب/91 (1)، دور معلم الأساس في توظيف لعب الدور في تنمية التفكير في الدرس، رسالة المعلم، المؤسسـة الصحفية الأردنية

$$
\text { - المجلد/بr، العدد/ء. }
$$

ـ و ادي، علي أحمد ( ـ . ب ) أثر العلاج المعرفي السلوكي في اضطر ابات القلق لدى الثباب اليمني، كلية التربية ، ابن رشد ، جامعة بغداد (اطروحة دكتوراه ). المصادر الأجنبية:

-Adam's , G . S . (197६) measurement and . education in education psychology, and dui dance, holl Rinehart \& Winston , New York.

-Ahman ,SJ Marrin,D.C( ( 9ソ०):measuring and Evalaying Educational achivementrand Baston.

-Anastasi,A( ( १९५):Psychologica testing Macmillan,publishing ,New York.

-Black, S., (19Аr), short-term couseling A Humanistic Approach for the helping professions, california Addison-wesley publishing company, Medical, Nursing Division

-Buss, A, H. (1971): The Psychology of aggression, John Wiley and Sons, New York

-Davidoff, L.Linda ( 9 १^). Introduction to psychology. Auckland: MC Graw-Hill. International Book Company

-Ebel , R.L. ( $19 Y$ Y ) : Essential of Educational measurement New Jerrsey, previssive hall , Inc

-Ellis( $(9$ १ r) Grop Rational - Emotive and Cognitive Behavioural International Journal of Group. therapy

-Ghisellie, et.al, ( $(9 \wedge)$ ): Measurement Theory for behavioral science. H. freeman and company. SanFrancisco

-Goldstein, A, P ( 9 १ᄉ ) psychology skills, perganon press, New York

-Guilford, J.P.(190乏) : psychometric methods New York Mc Graw - Hill printing house

-Hallahan, D \& Kouffman, J. , (1991).: Exceptional Children ,

Prentice Hall Inc( $r$ nd ed, N.J

-Heward, W., Orlansky, M. (1997): Exceptional Children, Bell \& Howell company. Ohio, U.S.A

-H-willough m Robert ( $(9 \wedge)$ ) Child behavior, learning and development Wlliamc. Sheppard University of Virginia

-Jones, R, ( (१^ץ) Practical counselling skill, Apschological skills approach for the helping protession and for voluntary counsellor, E, P. B, Holt Rinehart and Winston, London

-Levitt, E.( 9 १^). Eugene: the psychology of Auxiety. Publishers Hillsdale New York

-Mohoney, N.( (9\^): Cognitive Behavior therapy for children, Journal of American Academy of child and adolescent Psychiatry. Vr $(9$

-Mowrer $m$ Doris (190.)good literature gr parents and children the boptist training union magazine,

-Nunnally , J.C.(19Y^) : Psychometric theory ,MC Graw-Hill, New York

Obliu, Lloyd.(1919).Family Violence chicago, press

-Reber . E\& rebar . A . ( $r \ldots 1)$ : Social cognition and children's aggression behavior . Journal f Child Development . Vol . ( O ) (

-Sargent, L, R (1991) social skills for school and community, division ment retardation desinoines Lowa, the council for exceptional a children

-Wstson ( 19 Y $)$ Adol escent Dersonality and Beharion minn eapolis, univer sity of mihnesota press

-Watson, R.I. (19v0): Psychology of the Child, New York and London.

-Yen Allen ( 19v9 ) : Introduction to Measurement Theory . California : Brooke Cole . 
ملحق|(1) مقياس قلق البطالة بصورته النهائية

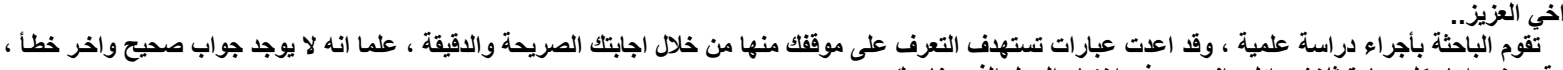

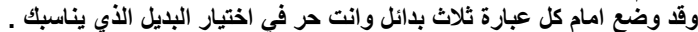

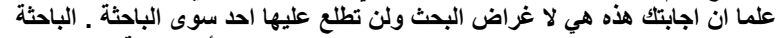

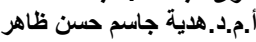

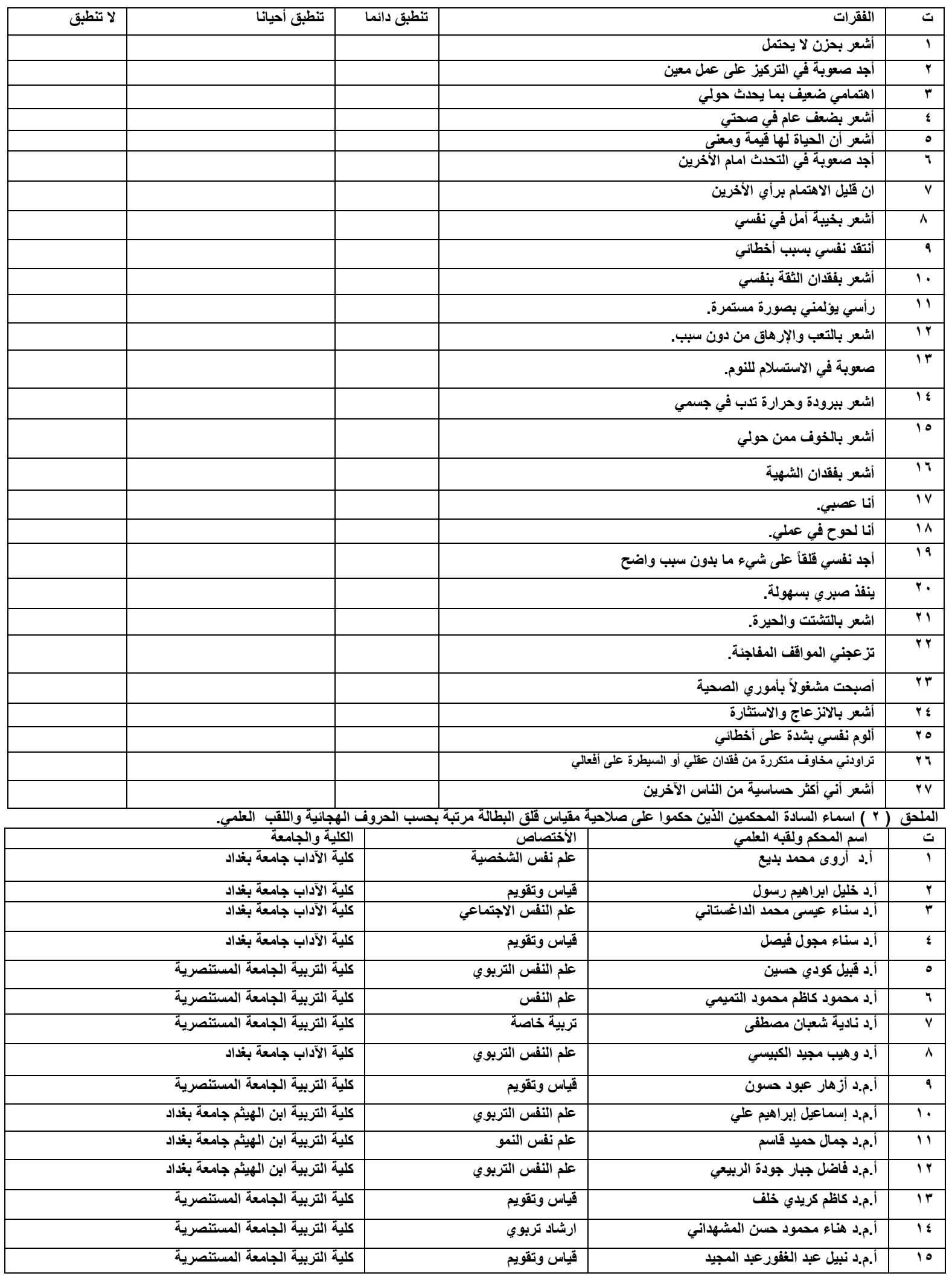

